\title{
Near Infrared Light Triggered Photo/Immuno-Therapy Toward Cancers
}

\author{
Xiaoxue $X u^{1 *}$, Hongxu Lu $u^{1}$ and Ruda Lee ${ }^{2}$ \\ ${ }^{1}$ Institute for Biomedical Materials and Devices, Faculty of Science, University of Technology, Sydney, NSW, Australia, \\ 2 International Research Organization for Advanced Science and Technology, Kumamoto University, Kumamoto, Japan
}

OPEN ACCESS

Edited by:

Qingxin Mu,

University of Washington

United States

Reviewed by:

Amit Jaiswal,

Indian Institute of Technology Mandi,

India

Gonzalo Ramírez-García,

Centro de Investigación en Química

Aplicada, Mexico

${ }^{*}$ Correspondence:

Xiaoxue Xu

xiaoxuehelen.xu@uts.edu.au

Specialty section:

This article was submitted to

Nanobiotechnology,

a section of the journal

Frontiers in Bioengineering and

Biotechnology

Received: 10 January 2020

Accepted: 27 April 2020

Published: 26 May 2020

Citation:

Xu X, Lu H and Lee R (2020) Near Infrared Light Triggered

Photo/Immuno-Therapy Toward

Cancers.

Front. Bioeng. Biotechnol. 8:488.

doi: 10.3389/fbioe.2020.00488
Nanomaterials-based phototherapies, mainly including photothermal therapy (PTT), photodynamic therapy (PDT) and photoimmunotherapy (PIT), present high efficacy, minimal invasion and negligible adverse effects in cancer treatment. The integrated phototherapeutic modalities can enhance the efficiency of cancer immunotherapy for clinical application transformation. The near-infrared (NIR) light source enables phototherapies with the high penetration depth in the biological tissues, less toxic to normal cells and tissues and a low dose of light irradiation. Mediated via the novel NIRresponsive nanomaterials, PTT and PDT are able to provoke cancer cells apoptosis from the generated heat and reactive oxygen species, respectively. The released cancerspecific antigens and membrane damage danger signals from the damaged cancer cells trigger immune responses, which would enhance the antitumor efficacy via a variety of immunotherapy. This review summarized the recent advances in NIR-triggered photo/immune-therapeutic modalities and their synergistic mechanisms and applications toward cancers. Furthermore, the challenges, potential solutions and future directions of NIR-triggered photo-/immunotherapy were briefly discussed.

Keywords: cancer phototherapy, near infrared light, photo/immune-therapy, photothermal therapy (PTT), photodynamic therapy, cancer

\section{INTRODUCTION}

Cancer is still one of the top leading causes of mortality after many decades' search and exploration for a cure in cancer from diagnosis and therapy. Currently, the available treatments to cancers in clinics are mainly surgery, chemotherapy and radiotherapy. A number of newly developed therapeutic modalities have been selectively adopted or in preliminary clinical trials including gene therapy, targeted therapy, immunotherapy, phototherapy (photothermal and photodynamic), magnetic hyperthermia therapy and other non-mainstream treatments.

The tumor cell death are caused in virtue of extrinsic stimuli in most of the aforementioned therapeutic modalities, such as chemotherapy mediated by chemotherapeutic agents, radiotherapy via various energy rays, hyperthermia therapy from the external high-frequency magnetic field, and phototherapy attributed to external light energy sources. Photothermal therapy (PTT) and photodynamic therapy (PDT) are the two representative phototherapy and are used for the tumor cells destruction through heat or reactive oxygen species respectively under irradiation of light. The external stimuli therapeutic approaches show significant advance in ablating solid primary tumors. However, the side effects from the extrinsic stimuli are quite strong and the recurrence of 
cancers is not controllable. Among the extrinsic stimuli, light energy in phototherapy offers lowest side effects and least systemic toxicity. Near-infrared (NIR) light is the preferable light source due to its superior tissue penetration ability. Under light irradiation, phototherapeutic agents that are little toxic in dark are turned into functional ones to selectively destroy cancer cells, without causing much damage to surrounding healthy tissues (Cheng et al., 2014).

While gene therapy and immunotherapy toward cancers are fulfilled owing to the intrinsic biological response of genes and immune systems to fight against cancers. Cancer immunotherapy approach, utilizing the patient's own immune system to trigger or enhance the antitumor response (Galluzzi et al., 2018; Sahin and Türeci, 2018), offers several advantages over the extrinsic therapeutic methods, such as low side effects, effective treatment of metastatic cancers, and generation of immunological memory to prevent recurrence (Jo et al., 2017). The five typical types of immunotherapies to treat cancer is summarized in Figure $\mathbf{1}$ (Sang et al., 2019). Systemic administration of cytokines is the first developed immunotherapy approach. Cytokines, such as interleukins (ILs) and interferon (INF), have shown significant antitumor activity via their immune regulation effects (Smyth et al., 2004). Therapeutic cancer vaccines are developed for active immunotherapies to treat late-stage cancers by harnessing the patient's own immune system, including peptide vaccines, whole tumor cell vaccines, dendritic cell (DC) vaccines and genetic vaccines (Guo et al., 2013). As the first Food and Drug Administration (FDA) approved therapeutic cancer vaccine, the DC-based vaccine sipuleucel-T (Provenge ${ }^{\circledR}$ ) has been used to treat prostate cancer since 2010 (Plosker, 2011), which may drive possible success for therapeutic vaccination strategies (Hollingsworth and Jansen, 2019; Mougel et al., 2019). Adoptive T cell transfer therapy (Kalos and Carl June, 2013) is an approach that $\mathrm{T}$ cells with specific chimeric antigen receptors are returned back to patient's body to eliminate cancer cells specifically after isolation, stimulation and reinfusion of tumor-infiltrating lymphocytes with potent antitumor activity. Recently, immune checkpoint pathways have entered the limelight in cancer immunotherapy because these immune checkpoint pathways control the amplitude and duration of immune responses to many cancers (Pardoll, 2012). Monoclonal antibodies, such as Ipilimumab targeting cytotoxic T lymphocyte-associated antigen 4 (CTLA-4) (Hodi et al., 2010), Atezolizumab targeting programmed death 1 (PD-1) receptor (Krishnamurthy and Jimeno, 2017), have been approved by FDA as immune checkpoint blocker for the treatments of metastatic melanoma and metastatic urothelial carcinoma or non-smallcell lung cancer, respectively. However, the immunomodulatory monoclonal antibodies have demonstrated severe immunerelated adverse effects on healthy cells (Postow et al., 2015).

To achieve the ultimate goal of eradicating primary tumors and metastasizes simultaneously, utilization of synergistic therapeutic modalities with extrinsic and intrinsic mechanisms for outstanding super-additive therapeutic effects to cancers is demanding and promising in current researches (Sang et al., 2019). Extrinsic stimuli can induce immunogenic cell death
(ICD) (Kroemer et al., 2013; Panzarini et al., 2013) which would release damaged-associated molecular patterns (DAMPs) thereby increase the immunogenicity of the tumor microenvironment from chemotherapy (Dudek et al., 2013), radiotherapy (Weiss et al., 2016), and phototherapy (Mroz et al., 2011). However, the resulting immune signals from the extrinsic stimuli are not sufficient and efficient to trigger the immune system for tumor erosion (Sang et al., 2019). Therefore, combining these cancer therapies with emerging immunotherapy is intuitive to overcome the limitations and maximize the merits of therapeutic modalities. From the point of view of low side effects, photoimmunotherapy (PIT), which is a synergistic therapy modality combining of phototherapy and immunotherapy toward cancers, demonstrates great potential benefits. While for the therapeutic window consideration, synergistic cancer therapy integrating phototherapy and immunotherapy would be the optimal. An optimal therapeutic window, quantified by therapeutic index, is critical to provide meaningful improvements in survival. Efforts should be aimed at increasing the therapeutic index, resulting in augmented efficacy in the elimination of primary tumor, metastasis of distant tumor and prevention of recurrence from long-term immune memory function. For the specific therapy modality, the therapeutic window can be improved from different aspects. For examples, the therapeutic index of PDT could be increased by extending the light delivery intervals (Ris et al., 1993). Exploitation of photosensitizers with low dark toxicities and high extinction coefficients may also allow the administration of higher doses of phototherapy agents and NIR light, resulting in higher therapeutic index (Boyle et al., 1992). An example is the use of Diiodo-substituted BODIPYs as a non-porphyrin photosensitizer for PDT improved the killing efficiency of melanoma B16F10 cells (Wang W. et al., 2016). Wei et al. (2019) reported a type of PIT agent, IR700-YY146, achieved high therapeutic index for melanomas of relatively smaller volumes. However, the treatment efficacy for larger tumors was not ideal due to the penetration of light through skin and tissues into the large tumor. Repeated treatment and increased the energy transfer ratio of the PIT agents may be helpful to treat large and deep tumors (Mallidi et al., 2016; Wei et al., 2019).

In this review, researches on NIR light-triggered photoimmunotherapy in last decade (2010 2019) toward cancers using nanomaterials are collected and discussed. We first describe the therapeutic effects on cancers using the synergistic PIT of immunotherapy with PDT and PTT followed with photochemistry-based cancer therapy. Lastly, a conclusion and future perspective are drawn at the end.

\section{PHOTOIMMUNOTHERAPY}

Phototherapy is a non-invasive or minimally invasive therapeutic strategy. In cancer treatment, phototherapy not only kill tumor cells directly but also induces ICD to initiate a systemic antitumor immune response, including the redistribution and activation of immune effector cells, the expression and secretion of cytokines 


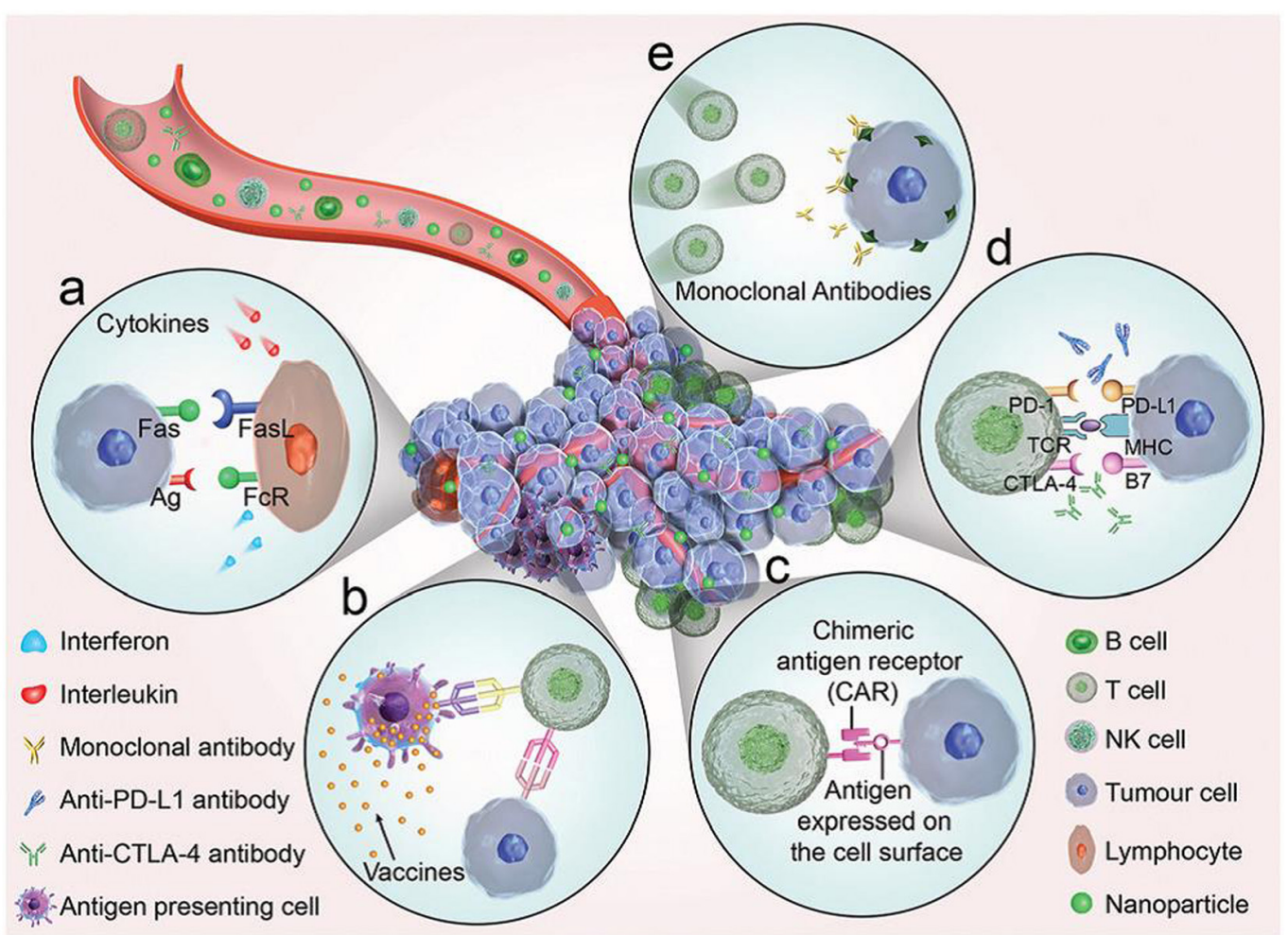

FIGURE 1 | An illustrated summary of the significant cancer immunotherapeutic approaches (Sang et al., 2019). The immunotherapies function through five key components (a) Cytokines, (b) Therapeutic vaccines, (c) Adoptive cell transfer. (d) Checkpoint blockade. (e) Binding between antibodies and tumor antigens. Reproduced with permission from reference Sang et al. (2019).

and the transformation of memory $\mathrm{T}$ lymphocytes (Hou et al., 2018; Li et al., 2019b).

Combining phototherapy and immunotherapy for cancer treatment, the merits of the two will be augmented while inherent shortfalls are minimized. The general principles that allow phototherapy to greatly enhance the immunotherapy effects have been summarized by Pu's group in a review (Ng et al., 2018) and the working mechanisms are shown in Figure 2. Firstly, phototherapy should be capable of effective eradication of primary tumors; Subsequently, the released tumor-specific antigens would serve as the substrates for an in situ autovaccine (Chen et al., 2016); Similarly, ICD during phototherapy would release DAMPs which are capable of triggering immune responses and thus strengthen the inherently weak immunostimulatory properties of native tumor antigens (Mroz et al., 2011); Lastly, the pro-inflammatory cytokines designed to activate the immune system are also elevated. On the other hand, immunotherapy then plays its part at the meantime with phototherapy via (1) increasing immunogenicity of the tumor microenvironment (utilizing immunoadjuvants), eventually attracting more antigen-presenting dendritic cells or (2) decreasing immunoregulatory suppression (immune checkpoint blockade therapy). In the last, the combined two therapeutic modalities could effectively eliminates the primary tumor, clears up residual tumor cells and tracks metastatic tumor sites. Phototherapy mainly is based on nanomaterials and nanotechnologies for their specific and selective effects on targeted disease lesion. Phototherapeutic modalities include PDT, PTT and photochemistry-based therapy, have attracted tremendous interest in both research and clinic aspects. The synergistic effects of each these phototherapeutic modalities with immunotherapy are discussed in the following sections respectively.

\section{Photothermal Therapy Synergized Immunotherapy}

PTT is one of the hyperthermia treatment to cancers through the administrated photoactive agents (Photosensitizers) that convert photon energy into thermal energy (Nam et al., 2019). Tumor cells can be killed at a temperature of $40-44^{\circ} \mathrm{C}$ with the invasive light irradiation, which would cause DNA damage, protein denaturation and plasma membrane disruption (Hildebrandt et al., 2002). In addition, the febrile temperature can trigger immune responses through the transcription of heat shock proteins and increased recruitment of lymphocytes to tissues with elevated temperature (Evans et al., 2015). The PTT induced tumor ablation can also induce the release of tumor antigens and immune-stimulatory molecules, thereby further activating the innate immunity and the adaptive immune system to kill residual or metastatic tumors (Hou et al., 2018). The photothermal-mediated immune response 


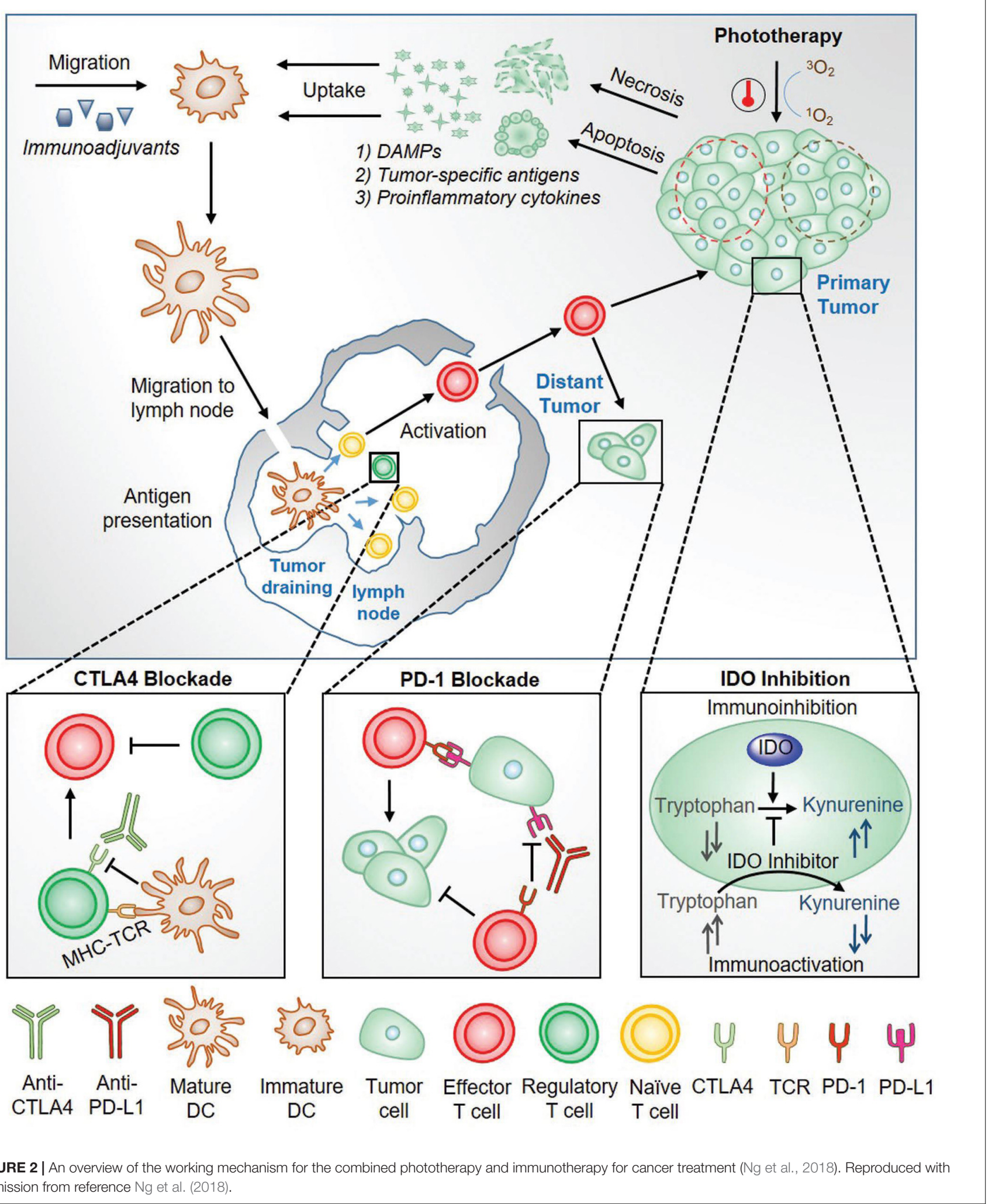

within the nanoparticles-based PTT has been illustrated in details by Rajendrakumar et al. (2018) and is shown in Figure 3.
NIR light has been widely used as the light source for PTT exhibiting minimal absorption and scattering by tissue components, thus NIR is able to achieve deep tissue penetration. 
A

\section{Immune response after PTT}

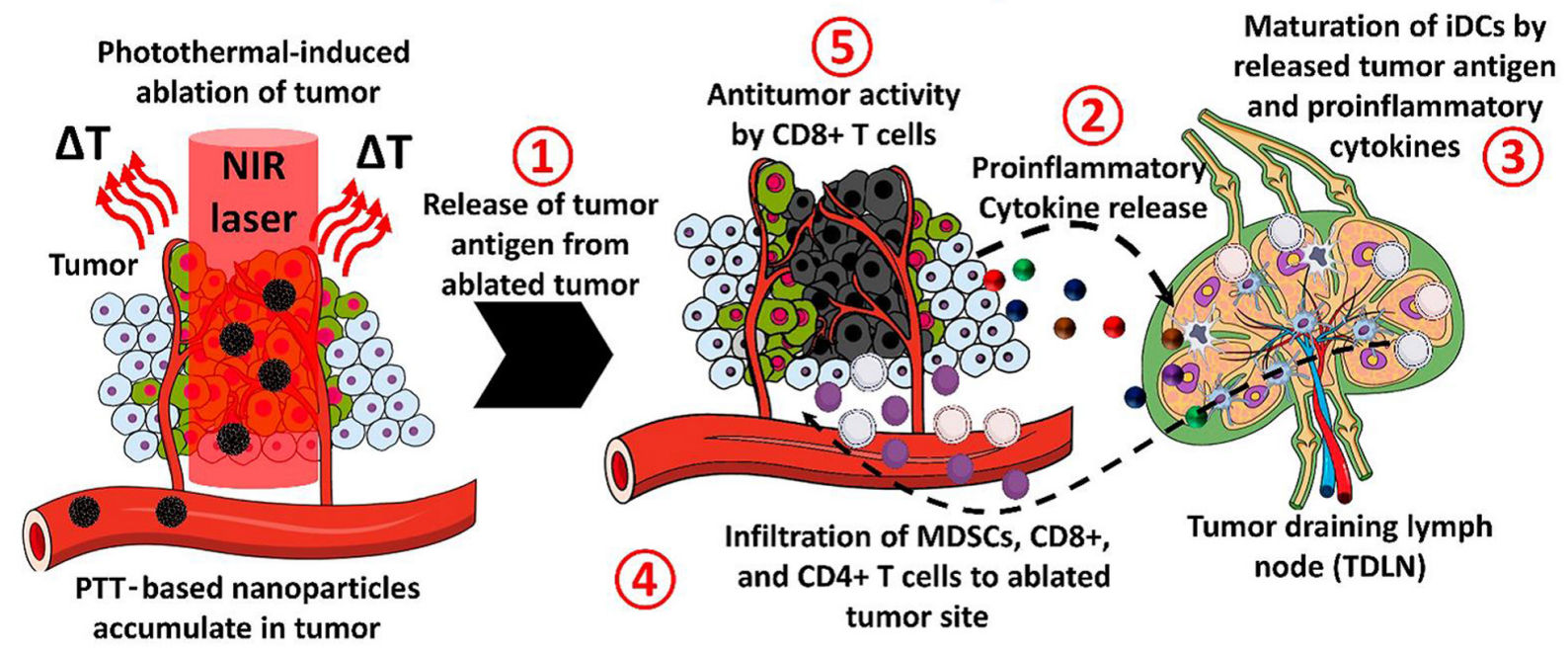

B

\section{Immune response after MDSC Infiltration}

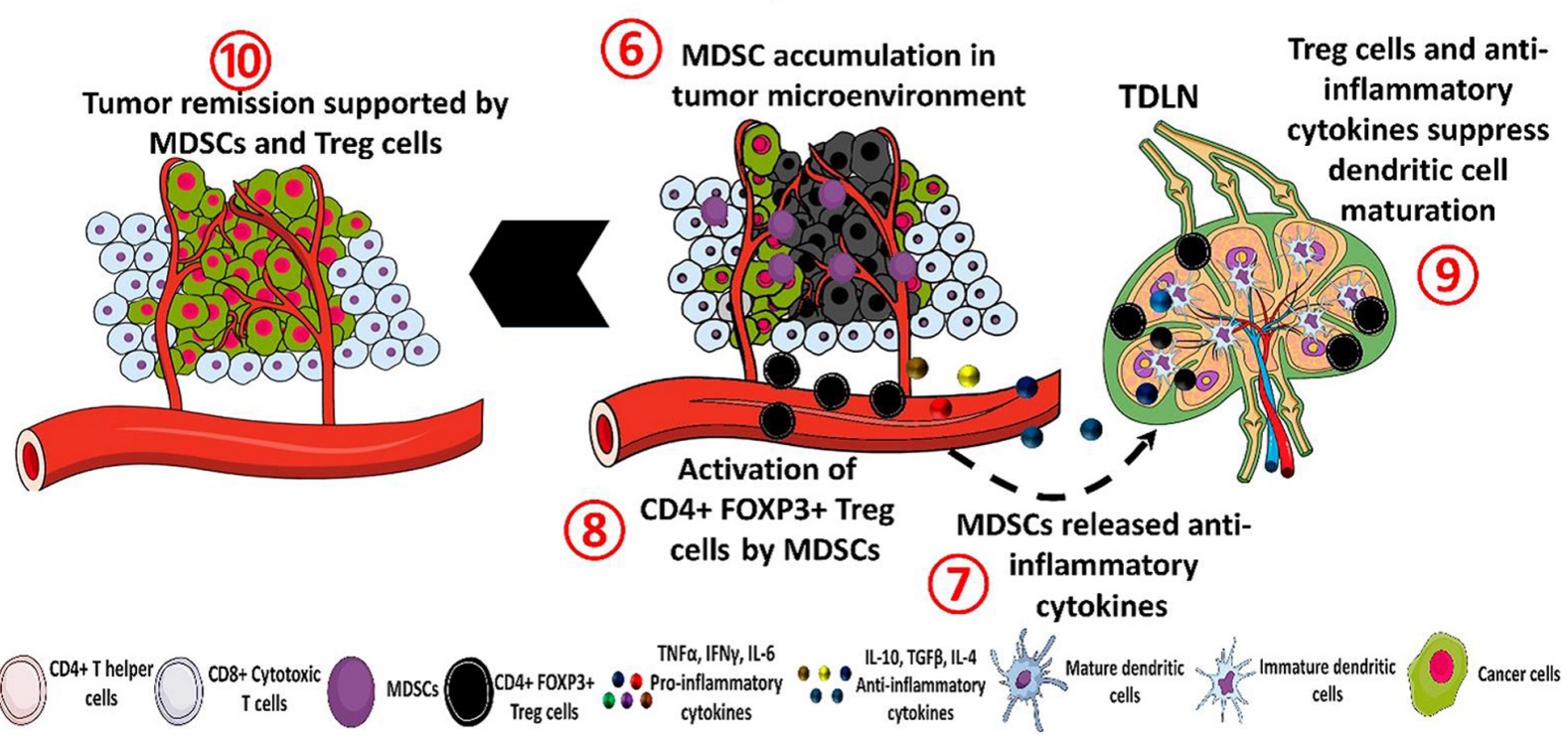

FIGURE 3 | The processes of immunotherapy mediated by nanoparticle-based PTT (A) and the tumor recurrence. There are eight steps to treat tumors after the PTT under NIR irradiation: (1) The ablated tumor cells release antitumor antigens (2) and proinflammatory cytokines. Then (3) the cytokines and antigens promote the maturation of dendritic cells in the tumor-draining lymph node (4) and help to recruit myeloid-derived suppressor cells (MDSCs) and CD8+ and CD4+ T cells. (5) The CD8+ T cells can induce an antitumor immune response. In the tumor recurrence, (6) the MDSC infiltrate in the tumor, (7) and release anti-inflammatory cytokines, (8) CD4 + FOXP3 + Treg cells are activated by MDSCs and inhibit the antitumor immune response, (9) the maturation of dendritic cells is blocked by anti-inflammatory cytokines and activated Treg cells, and (10) the overall action of MDSCs causes tumor remission (Rajendrakumar et al., 2018). Reproduced with permission from reference Rajendrakumar et al. (2018).

Bear et al. (2013) demonstrated an effective tumor ablation strategy which adopted optically tunable gold hollow nanoshells to generate heat upon exposure to NIR radiation $(808 \mathrm{~nm})$. The PTT subsequently promoted the expression of pro-inflammatory cytokines (IL-6, IL-1 $\beta$, IL-I2p70) and chemokines (CXCL1, CCL2, and CCL4) and induced maturation of dendritic cells within tumor-drain lymph nodes. Wang et al. (2014) also reported the photothermal ablation of primary tumors using single-walled carbon nanotubes (SWCNTs) that were able to strongly absorb NIR light of $808 \mathrm{~nm}$ and resulted in the release of tumor-associated antigens. However, the single model of NIRPTT induced immune response is insufficient to control the growth of the distal tumor or metastases owing to suboptimal activation. PTT promotes the generation of immunosuppressive 
myeloid-derived suppressor cells (Bear et al., 2013) and induces the temperature-dependent adverse effects on cytokines and chemokines (Nam et al., 2019).

The more effective way is to integrate the two therapeutic modalities, PTT and immunotherapy, together to target the primary tumor ablation as well as the metastatic cancer cell growth. The typical immunotherapy methods have been combined with PTT via either separate but subsequent administration or single and simultaneous administration. For example, the elimination of metastatic melanoma was achieved using gold nanoshell-enabled PTT together with adoptive T cell transfer immunotherapy $24 \mathrm{~h}$ following PTT (Bear et al., 2013). While a cytotoxic $\mathrm{T}$ lymphocyte antigen-4 (CTLA-4) blockade strategy was applied into mice with breast cancer or lung cancer after the tumor ablation by PTT, the antitumor efficacy was much promoted leading to effective rejection of secondary tumors and minimized tumor metastasis (Wang et al., 2014). An interventional PTT using an optical fiber with a NIR light of $980 \mathrm{~nm}$ was inserted into tumor center and an immunoadjuvant agent of glycated chitosan (GC) was intratumor-injected immediately after PTT in mouse pancreatic tumor model. The complete regression was achieved and more importantly, it triggered tumor-specific immune memory and the production of memory $\mathrm{T}$ cells to inhibit tumor rechallenge (Zhou et al., 2018). Ma et al. (2019) adopted a second NIR (NIR II at $1086 \mathrm{~nm}$ ) light to carry out the PTT. Compared to the red light $(680 \mathrm{~nm})$ and NIR I light $(808 \mathrm{~nm})$, NIR II light-triggered more homogeneous release and distribution of DAMPs from ICD in the deeper part of solid tumors via a gold photothermal transducer. The NIR II PTT combining with checkpoint blockade therapy enabled long-term tumor control over both primary and secondary tumors. Another NIR II transducer, polypyrrole nanosheets, showed striking therapeutic effects against whole-body tumor metastasis via the synergistic photothermal-immunological response.

Guo et al. (2014) integrated the immunoadjuvant oligodeoxynucleotides containing cytosine-guanine (CpG) motifs onto the NIR light-responsive photosensitizer, chitosancoated hollow $\mathrm{CuS}$ nanoparticles, and applied in a single dosage into a mouse breast cancer model. In this work, a pulsed NIR laser at $900 \mathrm{~nm}$ was employed. The hollow $\mathrm{CuS}$ absorbed the NIR light and conducted the PTT ablation to primary tumor. Upon the energy conversion, hollow CuS degraded into small nanoparticles and coated chitosan and the CpG assembled into chitosan-CpG nanocomplexes that potentiated host antitumor immunity against distant untreated tumors. The working mechanism is shown in Figure 4.

An immunoadjuvant agent, resiquimod R848, was loaded into the polydopamine nanoparticles as photothermal conversion agent together with carbon dots as imaging agent. Under $808 \mathrm{~nm}$ NIR light irradiation, the polydopamine can utilize hyperthermia to perform PTT to eliminate the primary 4T1 breast tumor cells. After the PTT, the generated and released tumor-associated antigens along with the PTT could be amplified by R848 and further triggered stronger infiltration of CTLs into distant tumors. In addition, The long-term immune memory effect was induced to prevent tumor reoccurrence (Lu et al., 2019).

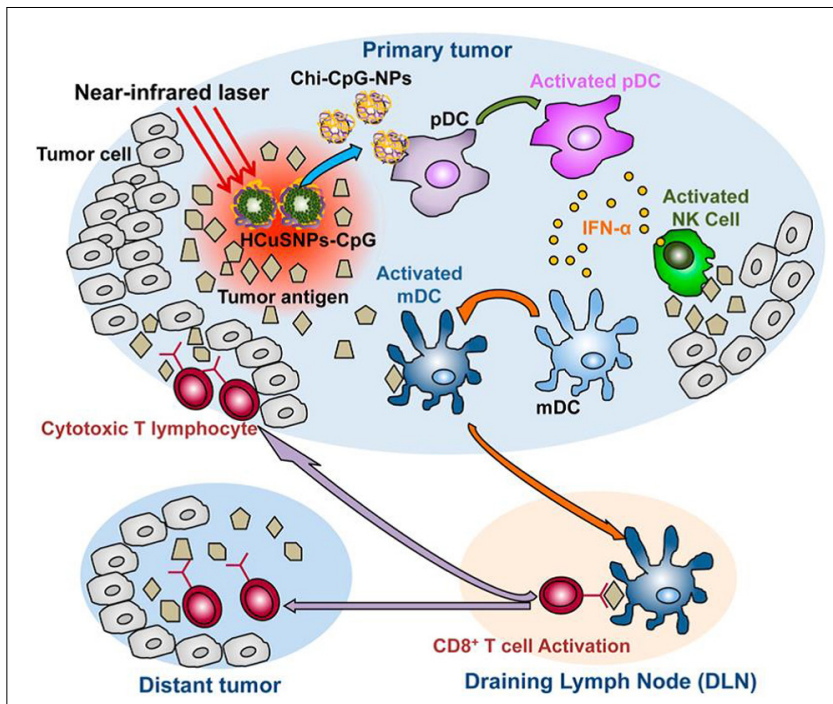

FIGURE 4 | A schematic of the immunotherapy to both primary treated and distant untreated tumors mediated by chitosan-coated hollow CuS nanoparticles loaded with $\mathrm{CpG}$ (HCuSNPs-CpG). Upon the irradiation of $900 \mathrm{~nm}$ NIR light, the intratumorally injected HCuSNPs-CpG transformed to chitosan-CpG nanocomplexes (Chi-CpG-NPs) that can be internalize into Toll-like receptor 9-rich endosomes of plasmacytoid dendritic cells (pDCs). These dendritic cells produce interferon-R (IFN-R) by the stimulation with $\mathrm{CpG}$, which can promote innate immunity through neutral killer (NK) cell activation. Meanwhile, the photothermal ablation by irradiated CuP nanoparticles destroys the tumor cells and releases tumor-associated antigens to attract and activate myeloid dendritic cells (mDCs). These mDCs become antigen-presenting cells with the help of IFN-R secreted by the pDCs. The antigen-presenting mDCs then migrate to tumor-draining lymph nodes (DLNs) and activate tumor antigen-specific T cells. These CD8 ${ }^{+} \mathrm{T}$ cells enter the systemic circulation and migrate to both primary tumor and distant tumor sites to provoke the "effector phase" of the adaptive immune response (Guo et al., 2014). Reproduced with permission from reference Rajendrakumar et al. (2018).

Two different immunotherapy methods can be synergized with PTT to effectively suppress primary tumors and to inhibit metastasis. Li et al. (2019a) investigated the use of the immunoadjuvant agent, glycated Chitosan (GC), modified SWCNTs with NIR laser irradiation to potentiate anti-CTLA checkpoint blockade therapy in a highly aggressive 4T1 murine breast cancer model. The SWCNTs was adopted to achieve selective ablation of primary tumor by locally absorbing a $1064 \mathrm{~nm}$ NIR light and the release of tumor antigens in the tumor microenvironment, while the GC further stimulated the host immune cells and induced antitumor immune response. The combined use of anti-CTLA checkpoint blockade to suppress the activity of immunosuppressive regulatory $\mathrm{T}$ cells induced a systemic antitumor immunity which inhibited lung metastasis and prolonged the animal survival time.

Although the PTT induced immunotherapy efficacy is low and weak, the combined PTT with different immunotherapy has achieved substantial immune stimulation and overcome immunosuppression within the tumor microenvironment. More efforts are still required to explore synergistic and efficient PTT and immunotherapy. 


\section{Photodynamic Therapy Synergized Immunotherapy}

PDT has been approved by the FDA for advanced cancer patients and it has been applied in clinic for various diseases with unique advantages in minimal invasiveness, low toxic side effects, good selectivity, and reproductivity (Park et al., 2018). In PDT, a photosensitizer (PS) is essentially employed to absorb the specific light energy for the generation of cytotoxic reactive oxygen species (ROS), such as singlet oxygen, $\mathrm{H}_{2} \mathrm{O}_{2}$ and hydroxyl and superoxide anion radicals (Chatterjee et al., 2008; Qiu et al., 2018). The ROS damages subcellular organelles and plasma membranes, thereby induce oxidative-stress-based cell death and destroy the functions of vascular surrounding the tumors. The dying tumor cells release tumor antigens and cytosolic components that provoke inflammation and stimulate immune systems. The illustration for PDT-mediated immune response following tumor necrosis after PDT is shown in Figure 5 (Rajendrakumar et al., 2018).

Similar to the PTT, PDT alone induces the relatively weak and insufficient immune response to inhibit distant metastasis while combined PDT and immunotherapy demonstrate great potential for both the primary tumor ablation and metastatic cancer cells inhibition (Wang D. et al., 2016). Compared to the hydrophobic organic photosensitizers which can selectively target in specific intracellular organelles, such as tetrapyrrole and phenothiazinium, the inorganic photosensitizers show improved PDT performances in targeted delivery and accumulation in tumor tissues and specific subcellular compartments and also in increased colloidal stability and photoresponsiveness (Abrahamse and Michael Hamblin, 2016). Single PDT using gold nanocages@ $\mathrm{MnO}_{2}$ nanostructures as the photosensitizer was employed for enhanced PDT effect and boosted antitumor immune responses against metastatic triple-negative breast cancer. The primary problem targeted in this work was the local hypoxia tumor environment which not only severely decreased the PDT efficacy, but also caused immunosuppression by inhibiting $\mathrm{T}$ cells from entering tumor environment. The $\mathrm{MnO}_{2}$ shell degraded in the acidic ( $\mathrm{pH}$ 6.5) tumor microenvironment and generated massive oxygen which was utilized for the production of powerful ROS from the gold nanocages under the irradiation of NIR $808 \mathrm{~nm}$. The primary tumor could be destroyed by these ROS, at the same time, the immunogenic cell death-mediated antitumor immune response from DAMPs was elicited to inhibitate lung metastasis (Liang et al., 2018).

Upconversion nanoparticles (UCNPs) is an emerging luminescent nanomaterials with potential advantageous benefits for PDT. UCNPs are able to transfer the NIR light energy (commonly 980 or $808 \mathrm{~nm}$ NIR lights) into required high energy light (visible and ultraviolet lights) to excite the combined photosensitizers for the ROS generation. Xu et al. (2017) designed and constructed a multitasking UCNPs nanocomplex with a photosensitizer (Ce6) and a Toll-likereceptor-7 agonist (R837). The UCNP-Ce6-R837 nanocomplex was injected intratumorally into the tumor. Under $980 \mathrm{~nm}$ NIR light irradiation, the effective PDT destruction of the tumor can generate a pool of tumor-associated antigens, which was powered by the adjuvant of R837 to stimulate strong antitumor immune responses. Further combined with the checkpoint blockade immunotherapy method with CTLA-4, it has been achieved for the excellent efficacy in eliminating tumors exposed to the NIR laser and also in inhibiting the growth of distant tumors through stimulated antitumor immunities as well as long term immune memory function from reoccurrence of colorectal cancer. The working mechanism is shown in Figure 6. Lin's group (Ding et al., 2018) designed large pore silica coated UCNPs based nanovaccine system in which photosensitizer, model protein (chicken ovalbumin, OVA) for $\mathrm{T}$ cell and cytokine evoke measurement and therapeutic vaccine to tumor (tumor cell fragment) could be loaded with much high loading efficiency (30 and $33.5 \%$ respectively). Both the great cellular uptake and the largely loading capacities of the prepared UCNPs-MC540 enabled much improved PDT efficacy, enhanced synergistic immunopotentiation actions to $\mathrm{T}$ cells and cytokines, and significant in vivo antitumor-therapy efficacy under $980 \mathrm{~nm}$ NIR irradiation.

The limitations for the PDT exist in the biosafety concern of photosensitizers, the penetration depth of the light source (NIR light can penetrate around $1 \mathrm{~cm}$ penetration in tissues), and less efficacy to large solid tumors. In spite of these limitations, PDT combining with immunotherapy is still a promising approach for advanced cancer treatment (Sang et al., 2019). A great deal of efforts has been contributed to develop biocompatible photosensitizers and optimize the light source type and power for penetrations in tissues and tumors.

\section{Photochemistry-Based Therapy Synergized Immunotherapy}

Other than the two typical phototherapy modality, PTT and PDT, NIR light is also adopted to trigger antitumor immunity as photo-immunotherapy toward cancers. NIR light was used to initiate photochemistry reactions of the photosensitizer and thus induce the immunotherapy. Kobayashi's group (Kobayashi and Choyke, 2019) proposed a new molecularly targeted cancer photo-therapy, NIR-PIT, which is based on a NIR silica-phthalocyanine dye, IR Dye 700DX (IR700), conjugated to cell-surface molecules targeting monoclonal antibody (mAb) (Ogata et al., 2017). The water-soluble conjugated $\mathrm{mAb}$ with IR700 was injected into the body and the mAb targeted an expressed antigen on cancer cell surfaces. The working mechanism of the NIR-PIT is presented in Figure 7 (Sato et al., 2018). Subsequent local exposure to NIR light would photodegrade the IR700 molecules by releasing the hydrophilic side chains, which converted the IR700 molecules on the cancer cell surfaces into hydrophobic. This conversion from hydrophilicity to hydrophobicity quenched the IR700 fluorescence due to the formation of a Z-stack multimer of silicon-phthalocyanine IR700 rings or water-insoluble aggregates of antibody-photo absorber conjugate (APC) or APC-antigen complexes. The cell membrane integrity would 
A
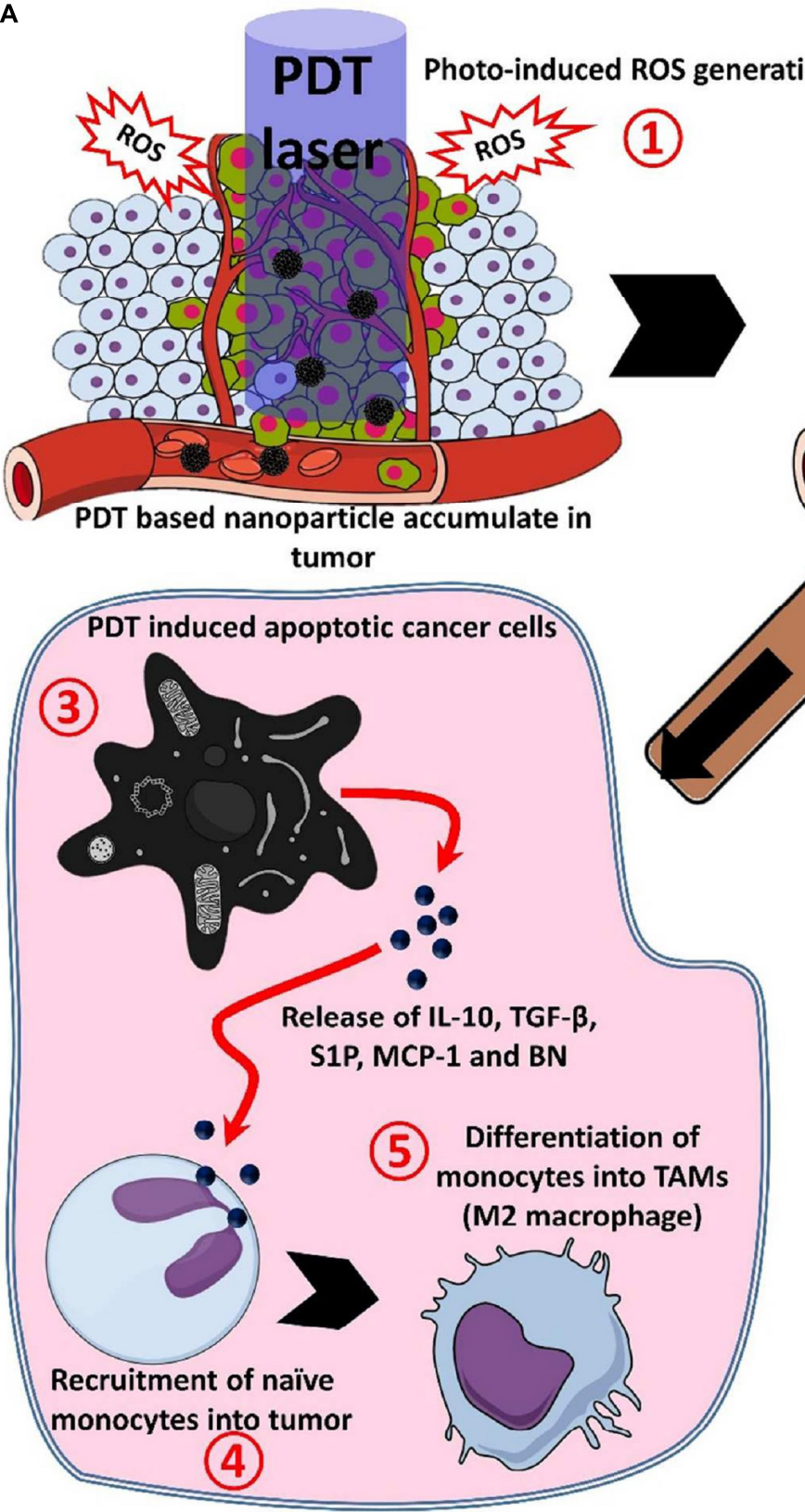

B

ROS induced cancer ROS induced apoptosis 


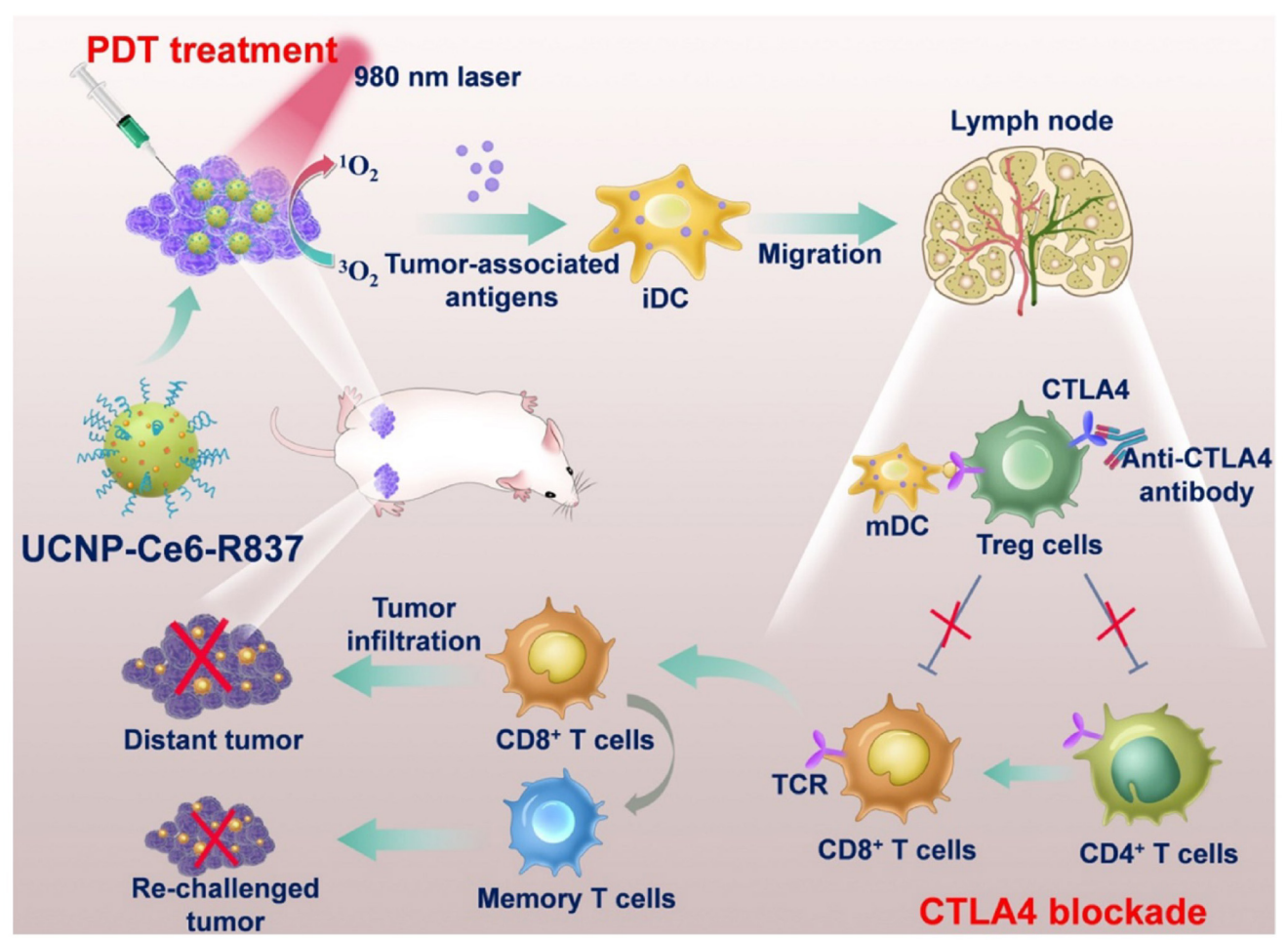

FIGURE 6 | A schematic describing the mechanisms of combining NIR-mediated PDT with CTLA-4 checkpoint blockade for cancer immunotherapy. NIR irradiation to UCNP-Ce6-R837 destroys tumor cells and generate tumor-associated antigens. The R837 acts as the adjuvant to stimulate antitumor immune response. Incorporation with the CTLA-4, UCNP-Ce6-R837 can inhibit both primary and distant tumors as well as preserve a long-term immune memory to prevent tumor relapse (Xu et al., 2017). Reproduced with permission from reference Xu et al. (2017).

human heavy chain antibody for hepatocellular cancer (Nagaya et al., 2016b).

NIR-PIT was also combined with an immunotherapeutic method of checkpoint blockade (Nagaya et al., 2019). NIRPIT monotherapy inhibited tumor growth, promoted tumor infiltration of dendritic cells, and induced de novo tumor antigenspecific T-cell responses absent at baseline. The addition of PD-1 blockade reversed adaptive immune resistance, resulting in both enhanced pre-existing tumor antigen-specific T-cell responses and enhanced de novo T-cell responses induced by NIR-PIT.

Chu et al. (2019) reported an activatable engineered immunodevice that enabled remotely control over the antitumor immunity in vivo with NIR light mediated using upconversion nanoparticles (UCNPs). It was a smart system with superior spatiotemporal precision and enhanced safety. The working mechanism scheme is displayed in Figure 8 (Chu et al., 2019). The immunodevice was composed of an immunotherapeutic agent, CpG oligonucleotides (ODNs), a complementary ssDNA (PcDNA) containing photocleavable bonds to yield PCpG, and UCNPs. The CpG was hybridized with the PcDNA firstly forming PCpG which then was integrated onto the UCNPs via cationic polymers. The constructed PCpG/UCNPs immunodevice could facilitate the delivery of PCpG into cells. After the cell uptake of the PCpG/UCNPs, upon the irradiation of NIR light $(980 \mathrm{~nm})$, the UCNPs converted the NIR to UV light to break the bond of the PcDNA and $\mathrm{CpG}$ and released the $\mathrm{CpG}$ inside of the cells. Thereafter, the $\mathrm{CpG}$ agent started to play its role for the immunotherapy to $4 \mathrm{~T} 1$ tumor with remotely spatially selective control. This non-invasive strategy presented high spatiotemporal precision and amenable personalizing antitumor function with reduced systemic toxicity.

The photochemistry based immunotherapy shows as high potential as the PTT and PDT with less complexity in nanomaterials design and working processes. More advanced photochemistry-based immunotherapy modality should be working on.

\section{Multiple Phototherapy Synergized Immunotherapy}

The implantation of multi-synergistic therapy relies on the combination of multiple treatments into a single nanoplatform. There are more than two phototherapeutic modalities have been integrated with immunotherapy.

Synergistic therapy integrating multiple NIR photoactivatable immunotherapeutic strategy has been comprehensively investigated. Li et al. (2019) developed an organic semiconducting pro-nanostimulants (OSPS) platform for synergetic cancer therapy. The OSPS comprised a semiconducting polymer nanoparticle (SPN) core and an immune checkpoint inhibitor (NLG919) which was conjugated together by a singlet oxygen $\left({ }^{1} \mathrm{O}_{2}\right)$ cleavable linker. Upon NIR 

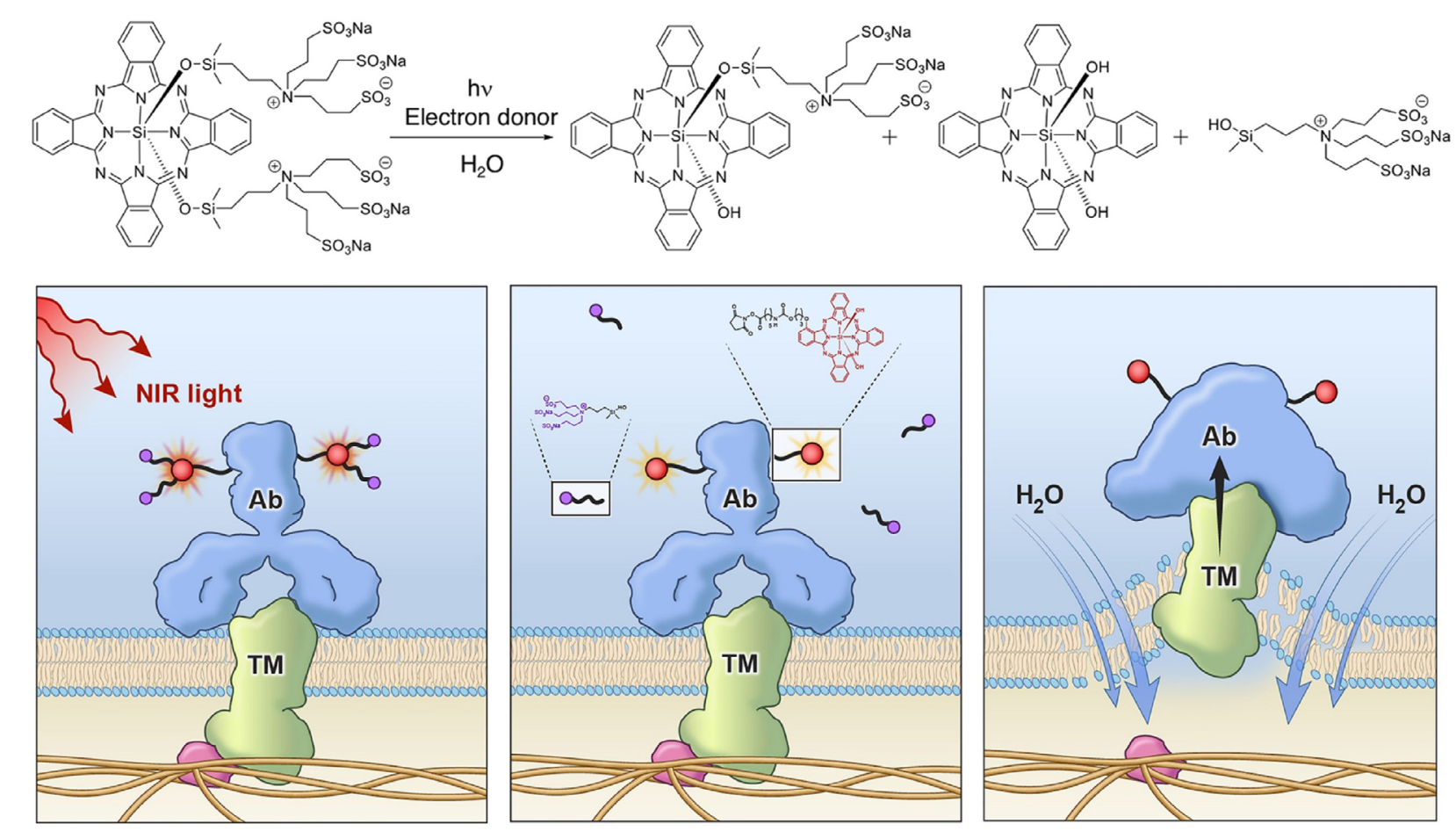

FIGURE 7 | A schematic for the chemical reaction of NIR-PIT (top) and the mechanisms underlying the disruption of tumor cells (Liang et al., 2018). Reproduced with permission from reference Liang et al. (2018).

laser irradiation, the SPN core within OSPS could generate both heat and ${ }^{1} \mathrm{O}_{2}$ for combinational PTT and PDT of tumors, leading to the release of tumor-associated antigens. Meanwhile, the generated ${ }^{1} \mathrm{O}_{2}$ specifically cleaves the ${ }^{1} \mathrm{O}_{2}$-cleavable liner to trigger the on-demand release and simultaneous activation of caged NLG919, which resulted in the promoted proliferation and activation of effector $\mathrm{T}$ cell but suppression of Treg cells. Therefore, the synergistic phototherapy with remote-controlled immune checkpoint blockade therapy exerted an amplified therapeutic efficacy in inhibition of primary and distant tumor growth and lung metastasis (Li et al., 2019b) and the working mechanism is shown in Figure 9.

Targeting for the rational design of smart nanomaterial that could combine multimodal therapy and overcome their own inherent limitations, Chen et al. (2019) developed a multifunctional nanoplatform for synergistic phototherapy (PDT and PTT), and chemotherapy drug docetaxel (DTX) enhanced cytokine immunotherapy. Mesoporous $\mathrm{CuS}$ nanoparticles were adopted as the carrier for loading and delivering chemotherapy drug docetaxel (DTX) and PTT agent under $808 \mathrm{~nm}$ light irradiation. Folic acid molecules were modified onto the CuS for targeted delivery and accumulation to tumor site. The photosensitizer, polyethylenimine-protoporphyrin IX (PEI-PpIX), were then coated outside of the $\mathrm{CuS}$ nanoparticle and the $\mathrm{CpG}$ was further modified onto the CuS surface. The combination of the four therapeutic modalities in this nanocomplex was denoted as FA-CD@PP-CpG. Although the FA-CD@PP-CpG presented remarkably inhabitation to tumor growth without apparent side effects within a 4T1-tumor-bearing mouse model, it also showed the complicated conduction for individual therapies, such as the PDT and PTT under $650 \mathrm{~nm} 808 \mathrm{~nm}$ light irradiation respectively, chemotherapeutic drug and immunoadjuvent agent separately release. The synergistic effect could be improved.

Yan et al. (2019) composed a relatively simple hybrid nanosystem using polydopamine as core, UCNPs nanoparticles as the shell and the photosensitizer chlorin e6 (Ce6) as surface coating. Polydopamine could absorb the excitation $980 \mathrm{~nm}$ NIR light and also the emissions of visible light from UCNPs for PTT. The visible light emission from UCNPs under NIR excitation was able to excite the Ce6 for PDT. The specific core-shell nanostructure design allowed adequate photoabsorption for the heat conversion and ROS generation with NIR light irradiation. Incorporating with immune checkpoint blocked-based therapy, this nanosystem inhibited tumor recurrence and metastasis and extended the survival periods of tumor-bearing mice in metastatic mouse models (Yan et al., 2019). However, the relatively large size of the core-shell nanostructure might not be able to have high accumulative amount in tumor site when systematically administrated in living mice model.

To increase the immune response induced by phototherapy, an NIR-triggered antigen-capturing nanoplatform was designed and fabricated, using UCNPs as carrier, indocyanine green (ICG) as a light absorber, rose bengal (RB) as photosensitizer 

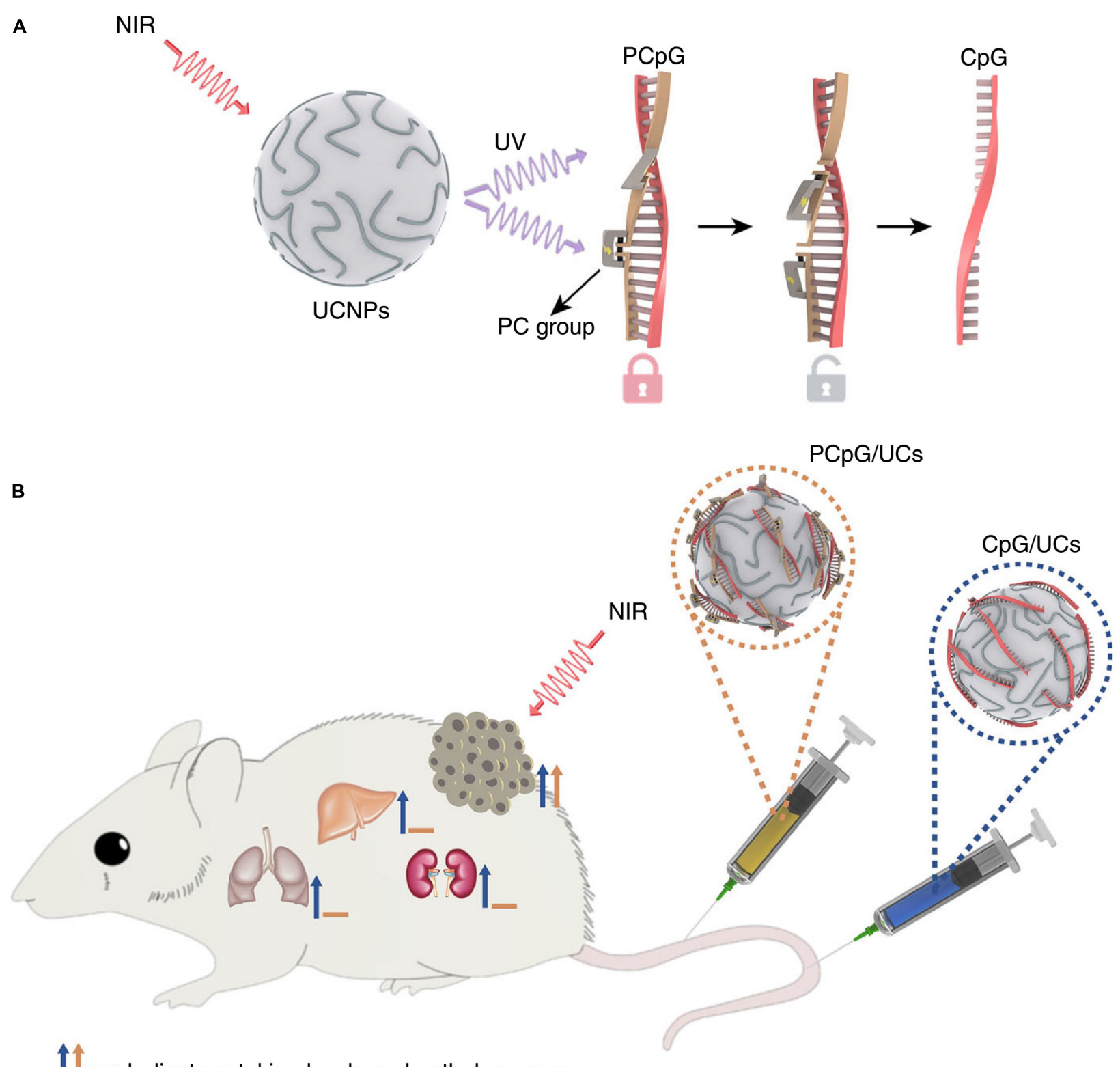

$\mathrm{PCpG} / \mathrm{UCs}$

- Indicate cytokine levels and pathology score

FIGURE 8 | The mechanism for the antitumor effects of the photoactivatable immunodevice, PCpG/UCs (A) and the in vivo activities for PCpG/UCs (B). PCpG/UCs can selectively trigger the immunoactivity through NIR light irradiation. In contrast to traditional CpG delivery system (CpG/UCs), PCpG/UCs showed reduced systemic toxicity (Chu et al., 2019). Reproduced with permission from reference Chu et al. (2019).

and the lipid molecule (DSPE-PEG-maleimide) as the antigen-capturing agent. The ICG significantly enhanced the RB-based PDT efficiency of UCNP/ICG/RB-mal under NIR irradiation, simultaneously achieving selective PTT effects. Most importantly, tumor-derived antigens released from the ablated tumor could be captured and retained in situ due to the functionality of maleimide. It would further enhance the tumor antigen uptake and recruitment of antigen-presenting cells, such as dendritic cells. The synergized photothermal, photodynamic, and immunological effects from NIR-activated UCNP/ICG/RB-mal induced tumor-specific immune responses and eliminated the primary distant tumors in using a 4T1-tumor mouse model (Wang et al., 2019).

A cascade bioreactor for synergistic cancer therapy combining chemo-dynamic therapy (CDT)/starvation therapy/phototherapy/immunotherapy was developed based on hollow structured $\mathrm{Cu}_{2} \mathrm{MoS}_{4}$ nanoparticles loaded with glucose oxidase (GOx) (Chang et al., 2019). The hollow $\mathrm{Cu}_{2} \mathrm{MoS}_{4}$ was well capable of chemical dynamic therapy from the generation of the hydroxyl radicals $(\mathrm{OH})$ through the chemical reactions of the redox couples of $\mathrm{Cu}^{1+} / 2+$ and $\mathrm{Mo}^{4+} / 6+$. The radicals also could deplete the overexpressed glutathione to modify the tumor 


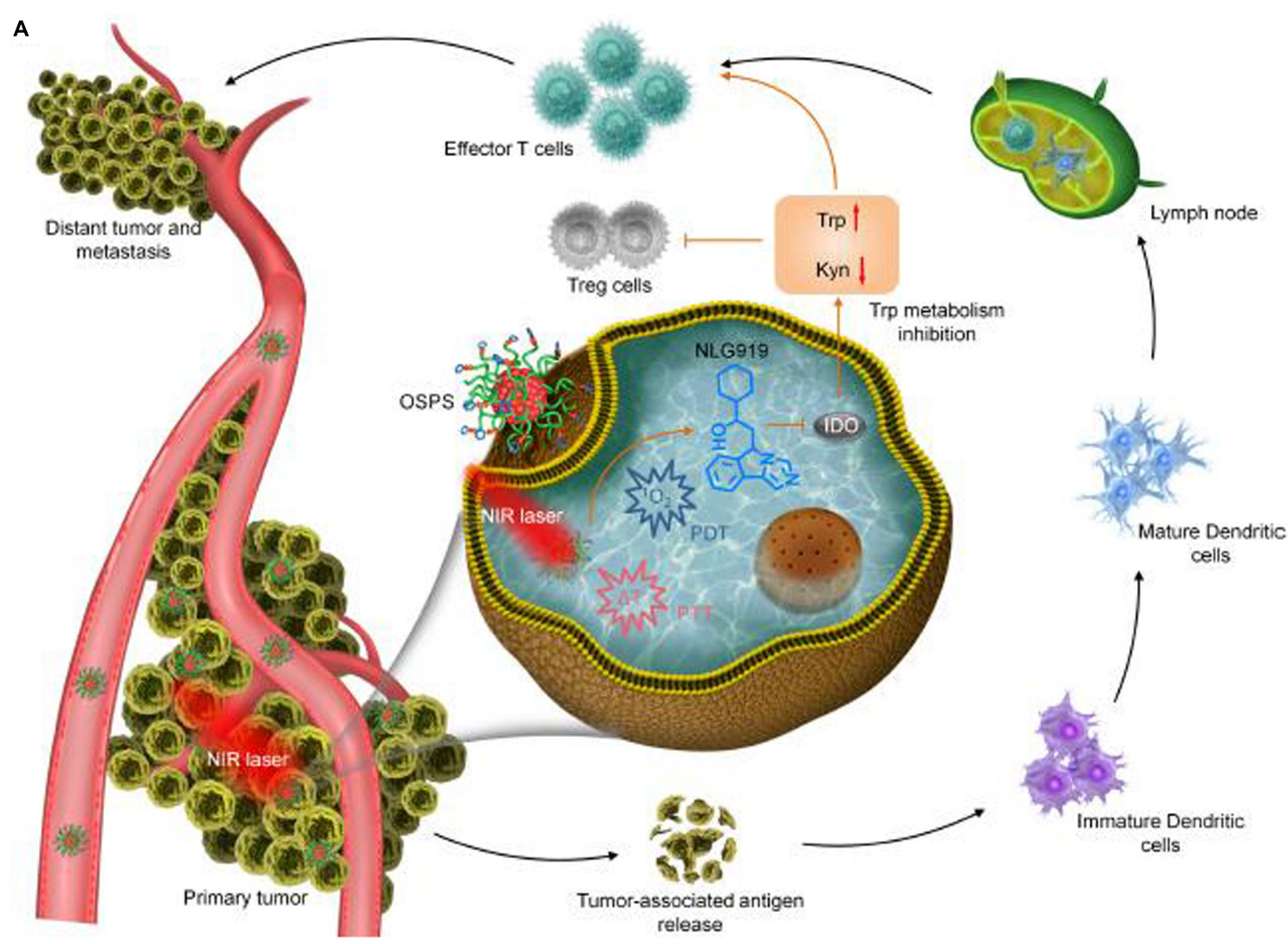

B

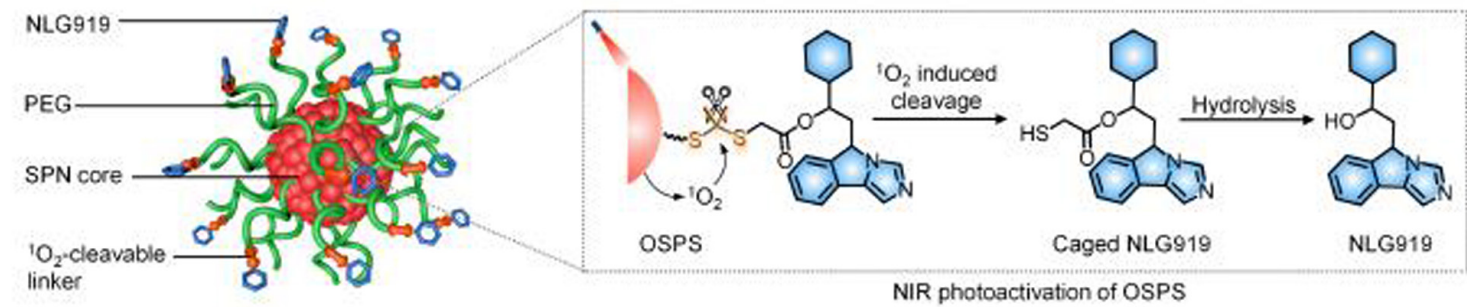

FIGURE 9 | The schematic illustration of the synergistic photo/immunotherapy using OSPS nanoplatform. (A) Illustration of photoactivation of OSPS for synergistic therapeutic action including phototherapy and checkpoint blockade immunotherapy. (B) Structure and NIR photo activation mechanism of OSPS (Li et al., 2019, \#45). Reproduced with permission from reference Li et al. (2019).

microenvironment aiming for the mitigation of antioxidant capability of the tumors.

Furthermore, the $\mathrm{Cu}_{2} \mathrm{MoS}_{4}$ could catalyze the reaction of endogenous $\mathrm{H}_{2} \mathrm{O}_{2}$ to $\mathrm{O}_{2}$ which would react with glucose and produce $\mathrm{H}_{2} \mathrm{O}_{2}$ again under the catalysis of GOx. The consummation of glucose could shut down nutrient supply to cancer cells and achieve starvation therapy. At the same time, the phototherapy effect of the $\mathrm{Cu}_{2} \mathrm{MoS}_{4}$ under $1064 \mathrm{~nm}$ NIR light irradiation was demonstrated by the strong tumor-killing capacity due to its excellent photothermal conversion efficiency. More importantly, the PEGylated $\mathrm{Cu}_{2} \mathrm{MoS}_{4} @ G O x$-based synergistic therapy combined with checkpoint blockade therapy could elicite robust immune responses for both effectively ablating primary tumors and inhibiting cancer metastasis.
The aforementioned photo/immunotherapy are summarized in Table $\mathbf{1}$ including the PDT synergized immunotherapy, PTT synergized immunotherapy, photochemistry based therapy synergized immunotherapy and multiple phototherapy synergized immunotherapy.

\section{PERSPECTIVES AND CONCLUSION}

Challenges and promising solutions are ahead of the success of photo/immunotherapy in cancer treatment. One of the major challenges is the lack of clinical trial results. Preclinical research in animals has shown that the photoimmunotherapy can eliminate tumor cells and enhance tumor-cell-selective systemic host-immunity leading to boosted antitumor effects 
TABLE 1 | Summary of near infrared light triggered photoimmuno-therapy toward cancers.

\begin{tabular}{|c|c|c|c|c|c|c|}
\hline $\begin{array}{l}\text { Phototherapy } \\
\text { Model }\end{array}$ & $\begin{array}{l}\text { Immunotherapy } \\
\text { Model }\end{array}$ & $\begin{array}{l}\text { Mediated } \\
\text { Nanomaterials }\end{array}$ & $\begin{array}{l}\text { NIR light } \\
\text { source }\end{array}$ & Targeted Cancer & Effectiveness & References \\
\hline \multirow[t]{8}{*}{ PTा } & Adoptive cell transfer & Gold nanoshells & $808 \mathrm{~nm}$ & Metastatic Melanoma & - Elimination of metastatic melanoma & Bear et al., 2013 \\
\hline & Checkpoint blockade & PEGylated SWNTs & $808 \mathrm{~nm}$ & Lung metastasis model & $\begin{array}{l}\text { - Effective rejection of secondary tumors } \\
\text { - Minimized tumor metastasis }\end{array}$ & Wang et al., 2014 \\
\hline & Therapeutic vaccines & Optical fiber & 980 nm & $\begin{array}{l}\text { Pancreatic tumor } \\
\text { model }\end{array}$ & $\begin{array}{l}\text { - Complete regression of primary tumor } \\
\text { - Triggered tumor-specific immune memory and production of } \\
\text { memory T cells }\end{array}$ & Zhou et al., 2018 \\
\hline & \multirow[t]{2}{*}{ Checkpoint blockade } & Gold nanoparticles & \multirow[t]{2}{*}{$1086 \mathrm{~nm}$} & \multirow[t]{2}{*}{ Breast cancer model } & $\begin{array}{l}\text { - Long-term tumor control over both primary and } \\
\text { secondary tumors }\end{array}$ & \multirow[t]{2}{*}{ Ma et al., 2019} \\
\hline & & Polypyrrole nanosheets & & & $\begin{array}{l}\text { - Striking therapeutic effects against whole-body } \\
\text { tumor metastasis }\end{array}$ & \\
\hline & Therapeutic vaccines & $\begin{array}{l}\text { Chitosan-coated hollow } \\
\text { CuS nanoparticles }\end{array}$ & $900 \mathrm{~nm}$ & Breast cancer model & $\begin{array}{l}\text { - Combined anticancer effects against primary treated as well as } \\
\text { distant untreated tumors }\end{array}$ & Guo et al., 2014 \\
\hline & Checkpoint blockade & $\begin{array}{l}\text { Polydopamine-carbon } \\
\text { dots }\end{array}$ & $808 \mathrm{~nm}$ & Breast cancer model & $\begin{array}{l}\text { - Ablation of the primary tumor } \\
\text { - Amplified stronger infiltration of CTLs into distant tumors }\end{array}$ & Lu et al., 2019 \\
\hline & Checkpoint blockade & SWCNTS & 1064 nm & $\begin{array}{l}4 \mathrm{~T} 1 \text { murine breast } \\
\text { cancer model }\end{array}$ & $\begin{array}{l}\text { - Effectively suppression on primary tumors } \\
\text { - Inhabitation of metastatic cancers }\end{array}$ & Li et al., 2019a \\
\hline \multirow[t]{3}{*}{ PDT } & - & Au nanocages @ $\mathrm{MnO}_{2}$ & $808 \mathrm{~nm}$ & $\begin{array}{l}\text { Metastatic } \\
\text { triple-negative breast } \\
\text { cancer }\end{array}$ & $\begin{array}{l}\text { - In situ oxygenation to ameliorate the hypoxia environment in } \\
\text { tumor area } \\
\text { - High PDT efficacy and elicited antitumor immune response } \\
\text { - Elimination of primary tumor and inhabited lung metastasis }\end{array}$ & Liang et al., 2018 \\
\hline & Checkpoint blockade & $\begin{array}{l}\text { UCNPs + } \\
\text { Chlorin e6 }\end{array}$ & 980 nm & $\begin{array}{l}\text { Mouse colon } \\
\text { adenocarcinoma } \\
\text { (CT26) }\end{array}$ & $\begin{array}{l}\text { - Enhanced tissue penetration depth thus effective photodynamic } \\
\text { destruction of tumors } \\
\text { - The generated a pool of tumor-associated antigens, together } \\
\text { with CTLA4 resulted in strong antitumor immunities to inhibit the } \\
\text { growth of distant tumors } \\
\text { - A long-term immune memory function to protect treated mice } \\
\text { from tumor cell rechallenge }\end{array}$ & Xu et al., 2017 \\
\hline & vaccine & $\begin{array}{l}\text { UCNPs@large pore } \\
\text { silica + merocyanine } \\
540+\text { OVATF agent }\end{array}$ & 980 nm & $\begin{array}{l}\text { Mouse colon } \\
\text { adenocarcinoma }\end{array}$ & $\begin{array}{l}\text { - Largely load photosensitizer and immune antigens } \\
\text { - Great cellular uptake } \\
\text { - Enhanced immunotherapy efficacy and new approach to } \\
\text { advanced vaccine delivery system for cancer therapy }\end{array}$ & Ding et al., 2018 \\
\hline
\end{tabular}


TABLE 1 | Continued

\begin{tabular}{|c|c|c|c|c|c|c|}
\hline $\begin{array}{l}\text { Phototherapy } \\
\text { Model }\end{array}$ & $\begin{array}{l}\text { Immunotherapy } \\
\text { Model }\end{array}$ & $\begin{array}{l}\text { Mediated } \\
\text { Nanomaterials }\end{array}$ & $\begin{array}{l}\text { NIR light } \\
\text { source }\end{array}$ & Targeted Cancer & Effectiveness & References \\
\hline \multirow[t]{3}{*}{ PCT } & Monoclonal antibodies & $\begin{array}{l}\text { Silica-phthalocyanine } \\
\text { dye (IR700) }\end{array}$ & $690 \mathrm{~nm}$ & $\begin{array}{l}\text { B-cell lymphoma, } \\
\text { prostate cancer, } \\
\text { hepatocellular cancer }\end{array}$ & $\begin{array}{l}\text { - Photosensitizer molecule was conjugated to monoclonal } \\
\text { antibodies } \\
\text { - Photochemistry therapy destructed the primary tumor within } \\
1 \text { min under NIR irradiation }\end{array}$ & $\begin{array}{l}\text { Hanaoka et al., 2015; } \\
\text { Nagaya et al., 2016a,b, } \\
\text { 2017; Ogawa et al., } \\
\text { 2017; Sato et al., } 2018\end{array}$ \\
\hline & Checkpoint blockade & $\begin{array}{l}\text { Silica-phthalocyanine } \\
\text { dye (IR700) conjugated } \\
\text { with anti-CD44 }\end{array}$ & $690 \mathrm{~nm}$ & Colon and lung cancer & $\begin{array}{l}\text { - Elimination of primary tumor } \\
\text { - Durable antitumor immunity eradicated both treated and distant } \\
\text { untreated tumors }\end{array}$ & Nagaya et al., 2019 \\
\hline & Cytokine & UCNPs/CpG & $980 \mathrm{~nm}$ & $\begin{array}{l}\text { Mouse } 4 \mathrm{~T} 1 \text { breast } \\
\text { cancer }\end{array}$ & $\begin{array}{l}\text { - Immunotherapeutic agents delivered into cancer cells and } \\
\text { released upon the remote NIR light irradiation. }\end{array}$ & Chu et al., 2019 \\
\hline PDT + PTT & Checkpoint blockade & $\begin{array}{l}\text { Organic } \\
\text { semidonducting } \\
\text { pro-nanostimulants }\end{array}$ & $\begin{array}{l}808 \mathrm{~nm} \\
\left(0.3 \mathrm{~W} / \mathrm{cm}^{2}\right)\end{array}$ & $\begin{array}{l}\text { Mouse } 4 \mathrm{~T} 1 \text { breast } \\
\text { cancer }\end{array}$ & $\begin{array}{l}\text { - With the small size }(26 \mathrm{~nm}) \text { and stealthy PEG surface, OSPS } \\
\text { could effectively accumulate into the tumors of living mice after } \\
\text { systemic administration. } \\
\text { - Upon the } 808 \mathrm{~nm} \text { light irradiation, PTT and PDT ablated the } \\
\text { primary tumor. } \\
-{ }^{1} \mathrm{O}_{2} \text { also cleaved the conjugated immunostimulant and inhibited } \\
\text { the growth of both primary and distant tumors and suppressed } \\
\text { lung metastasis. } \\
\text { - Low in vivo toxicity. }\end{array}$ & Li et al., 2019 \\
\hline $\begin{array}{l}\mathrm{PTT}+\mathrm{PDT}+ \\
\text { Chemotherapy }\end{array}$ & Checkpoint blockade & $\begin{array}{l}\text { Mesoporous } \\
\text { CuS + PEI- } \\
\text { PplX + DTX + CpG }\end{array}$ & $\begin{array}{l}808 \mathrm{~nm} \\
\text { and } \\
650 \mathrm{~nm}\end{array}$ & $\begin{array}{l}\text { Mouse } 4 \mathrm{~T} 1 \text { breast } \\
\text { cancer }\end{array}$ & $\begin{array}{l}\text { - Negligible toxicity to normal tissues } \\
\text { - Remarkable damage to tumors in vivo }\end{array}$ & Chen et al., 2019 \\
\hline $\mathrm{PTT}+\mathrm{PDT}$ & Checkpoint blockade & $\begin{array}{l}\text { Polydopamine }+ \\
\text { UCNPs }+ \text { Ce6 }\end{array}$ & $980 \mathrm{~nm}$ & $\begin{array}{l}\text { Mouse } 4 \mathrm{~T} 1 \text { breast } \\
\text { cancer }\end{array}$ & $\begin{array}{l}\text { - Significant eradication of the primary tumors from PDT and PTT. } \\
\text { - Effective delay to untreated distal tumor from the combined } \\
\text { checkpoint blockade therapy. }\end{array}$ & Yan et al., 2019 \\
\hline $\begin{array}{l}\mathrm{PTT}+\mathrm{CDT}+ \\
\text { starvation } \\
\text { therapy }\end{array}$ & Checkpoint blockade & $\begin{array}{l}\text { PEGylated } \\
\mathrm{Cu}_{2} \mathrm{MoS}_{4} @ \mathrm{GOx}\end{array}$ & $\begin{array}{l}1064 \mathrm{~nm} \\
\left(0.48 \mathrm{~W} / \mathrm{cm}^{2}\right)\end{array}$ & $\begin{array}{l}\text { Mouse cervix cancer } \\
\text { and lung metastasis } \\
\text { model }\end{array}$ & $\begin{array}{l}\text { - Great biosafety of the combined treatment approach. } \\
\text { - Effective primary tumor ablation from PTT, CDT and starvation } \\
\text { therapy; } \\
\text { - Inhabitation of distant tumor and lung metastasis. }\end{array}$ & Chang et al., 2019 \\
\hline PTT + PDT & Checkpoint blockade & $\begin{array}{l}\text { UCNPS + ICG + RB + } \\
\text { DSPE-PEG-maleimide }\end{array}$ & $805 \mathrm{~nm}$ & $\begin{array}{l}\text { Mouse } 4 \mathrm{~T} 1 \text { breast } \\
\text { cancer }\end{array}$ & $\begin{array}{l}\text { - Efficient destruction of primary tumor; } \\
\text { - Inhabitation of metastasis by simultaneously boosting specific } \\
\text { immune response and checkpoint blockade. } \\
\text { - Strong long-term antitumor immune memory function. }\end{array}$ & Wang et al., 2019 \\
\hline
\end{tabular}


triggered by NIR light. However, due to the species difference and complexity of human in vivo microenvironment, the performance of photoimmunotherapy in human is barely predicted. For example, Sato et al. (2014) compared the performance of two types of photoimmunotherapy agents, cetuximab-IR700 and panitumumab-IR700, in EGFR positive mouse tumor models. Although panitumumab-IR700 showed better antitumor efficiency than cetuximab-IR700 in the mice models, it is not possible to conclude their performance in human bodies (Sato et al., 2014). Luckily, a NIR-PIT using cetuximabIR700 (RM1929) targeting EGFR in inoperable recurrent head and neck cancer is in a phase III trial, which is currently underway in several countries in Asia, North America, and Europe (Kobayashi and Choyke, 2019). It is expected that more photoimmunotherapy agents will be tested in clinical trials and the results will bring more valuable information for immunotherapy research. In addition to the clinical trials, the recent progress in organoids and organ-on-chips research may also provide tools for the exploitation of photoimmunotherapy (Yin et al., 2016; Brassard and Lutolf, 2019).

Functional targeting moieties and targeting efficiency is another critical factor that would influence the localized treatment. The targeting moieties bind surface markers on the cancer cells, dominating the specificity and distribution of the photoimmunotherapy agents. Various targeting moieties including antibodies, peptides, functional molecules and oligonucleotides have been conjugated with the photoactivation complexes (Kobayashi and Choyke, 2019; Shirasu et al., 2019). More specific targeting moieties will be the key to improve the efficiency of eliminating cancer cells while to reduce the side effects to the healthy cells. Targeting moieties for circulating and metastatic cancer cells are also highly desired in order to promote the prognosis after photoimmunotherapy treatment. The recent advances have applied multiple targeting groups in the photoimmunotherapy agents, aiming for cancer cells and immunocytes, respectively. The stroma cells, such as cancerassociated fibroblasts, may also be considered as a target in the photoimmunotherapy treatment (Shirasu et al., 2019).

The nanomaterials provide a large pool of candidates as the photoactivated cores for photoimmunotherapy. The development of nanomaterials with low cytotoxicity, high photoactivity, and multifunctionality will facilitate the clinical application of cancer photoimmunotherapy. Proper NIR light is required for deep penetration into the tumour tissues, dependent on the nanomaterials applied in the therapy. The energy of NIR light dramatically decreases with the depth of the tissue, for example, NIR photoimmunotherapy through bone is limited to $3 \mathrm{~mm}$ when using $810 \mathrm{~nm}$ NIR of less than $1 \mathrm{~W}$ (Nakamura et al., 2019). Improving the energy transfer efficiency of nanomaterials is critical for the treatment of cancers in the deep body with NIR in the biosafety range. An example is

\section{REFERENCES}

Abrahamse, H., and Michael Hamblin, R. (2016). New photosensitizers for photodynamic therapy. Biochem. J. 473, 347-364. polydopamine coating improved the absorption capacity of gold nanoparticles, reported by Nam et al. (2019). It has been reported that IR700-formed APC showed a biodistribution similar to non-conjugated parental antibodies, once injected intravenously, the APC will have a sufficient accumulation in the tumors (Mitsunaga et al., 2011; Nagaya et al., 2018). However, it is still challenging for the nanomaterials-based phototherapy that the recognization and clearance of the nanomaterials by the cells in liver, spleen and other parts of the reticuloendothelial system (RES) may reduce the concentration of the therapeutics in the tumor sites. The intratumoral route of administration are generally chosen to overcome the RES uptake and low time blood circulation. In addition, nanomateriasl are often modified with PEG (PEGylation) (Gao et al., 2020) or zwitterionic polymers (Zheng et al., 2019) to hide the nanomaterials from the RES cells and to enhance the accumulation at tumors.

Well-integrated photo/immunotherapeutic modalities will benefit the single administration and working simultaneously. PTT and PDT, in combination with immunotherapies, provide infinite possibilities as a promising method to treat cancer. The administration or conjugation of antibodies or gene silencing agents aiming to immune checkpoint pathways with PTT and PDT open new windows for immunotherapy (Wang W. et al., 2016). However, the performance and efficiency of integrated strategies are not always comparable in terms of eradication of primary tumors, inconsistent results between different models, and difficulty in conjugating biomarkers. More comprehensive studies with integrated therapies will benefit the development of successful photoimmunotherapy agents.

The ultimate goal of the nanomaterials-based phototherapies is to eradicate cancers completely, including primary solid tumors and metastatic cancers. With minimized side effect and maximized treatment efficacy, phototherapy and immunotherapy are the two most promising therapeutic modalities and their synergistic combination of photoimmunotherapy has shown substantial potentials to realize the ultimate goal.

\section{AUTHOR CONTRIBUTIONS}

XX designed, structured, and wrote the manuscript. HL designed, structured, and revised the manuscript. RL designed and revised the manuscript.

\section{FUNDING}

This article was primarily supported by the Chancellor Postdoctoral Research Fellowship of University of Technology Sydney (XX).

Bear, A. S., Kennedy, L. C., Young, J. K., Perna, S. K., Mattos Almeida, J. P., Lin, A. Y., et al. (2013). Elimination of metastatic melanoma using gold nanoshellenabled photothermal therapy and adoptive T cell transfer. PLoS One 8:e69073. doi: 10.1371/journal.pone.0069073 
Boyle, R. W., Paquette, B., and van Lier, J. E. (1992). Biological activities of phthalocyanines. XIV. Effect of hydrophobic phthalimidomethyl groups on the in vivo phototoxicity and mechanism of photodynamic action of sulphonated aluminium phthalocyanines. Br. J. Cancer 65, 813-817.

Brassard, J. A., and Lutolf, M. P. (2019). Engineering stem cell self-organization to build better organoids. Cell Stem Cell 24, 860-876. doi: 10.1016/j.stem.2019. 05.005

Chang, M., Wang, M., Wang, M., Shu, M., Ding, B., Li, C., et al. (2019). A multifunctional cascade bioreactor based on hollow-structured $\mathrm{Cu}_{2} \mathrm{MoS}_{4}$ for synergetic cancer chemo-dynamic therapy/starvation therapy/phototherapy/immunotherapy with remarkably enhanced efficacy. Adv. Mater. 31:e1905271.

Chatterjee, D. K., Fong, L. S., and Zhang, Y. (2008). Nanoparticles in photodynamic therapy: an emerging paradigm. Adv. Drug Deliv. Rev. 60, 1627-1637. doi: 10.1016/j.addr.2008.08.003

Chen, L., Zhou, L., Wang, C., Han, Y., Lu, Y., Liu, J., et al. (2019). Tumortargeted drug and CpG delivery system for phototherapy and docetaxelenhanced immunotherapy with polarization toward m1-type macrophages on triple negative breast cancers. Adv. Mater. 31:1904997. doi: 10.1002/adma.20190 4997

Chen, Q., Wen, J., Li, H., Xu, Y., Liu, F., and Sun, S. (2016). Recent advances in different modal imaging-guided photothermal therapy. Biomaterials 106, 144-166. doi: 10.1016/j.biomaterials.2016.08.022

Cheng, L., Wang, C., Feng, L., Yang, K., and Liu, Z. (2014). Functional nanomaterials for phototherapies of cancer. Chem. Rev. 114, 10869-10939.

Chu, H., Zhao, J., Mi, Y., Di, Z., and Li, L. (2019). NIR-light-mediated spatially selective triggering of anti-tumor immunity via upconversion nanoparticlebased immunodevices. Nat. Commun. 10:2839. doi: 10.1038/s41467-01910847-0

Ding, B., Shao, S., Yu, C., Teng, B., Wang, M., Cheng, Z., et al. (2018). Largepore mesoporous-silica-coated upconversion nanoparticles as multifunctional immunoadjuvants with ultrahigh photosensitizer and antigen loading efficiency for improved cancer photodynamic immunotherapy. Adv. Mater. 30:1802479. doi: 10.1002/adma.201802479

Dudek, A. M., Garg, A. D., Krysko, D. V., De Ruysscher, D., and Agostinis, P. (2013). Inducers of immunogenic cancer cell death. Cytokine Growth Factor Rev. 24, 319-333.

Evans, S. S., Repasky, E. A., and Fisher, D. T. (2015). Fever and the thermal regulation of immunity: the immune system feels the heat. Nat. Rev. Immunol. 15, 335-349. doi: 10.1038/nri3843

Galluzzi, L., Chan, T. A., Kroemer, G., Wolchok, J. D., and López-Soto, A. (2018) The hallmarks of successful anticancer immunotherapy. Sci. Transl. Med. 10:eaat7807. doi: 10.1126/scitranslmed.aat7807

Gao, D., Guo, X., Zhang, X., Chen, S., Wang, Y., Chen, T., et al. (2020) Multifunctional phototheranostic nanomedicine for cancer imaging and treatment. Mater. Today Bio 5:100035. doi: 10.1016/j.mtbio.2019.100035

Guo, C., Manjili, M. H., Subjeck, J. R., Sarkar, D., Fisher, P. B., and Wang, X.-Y. (2013). Therapeutic cancer vaccines: past, present, and future. Adv. Cancer Res. 119, 421-475. doi: 10.1016/B978-0-12-407190-2.00007-1

Guo, L., Yan, D. D., Yang, D., Li, Y., Wang, X., Zalewski, O., et al. (2014). Combinatorial photothermal and immuno cancer therapy using chitosancoated hollow copper sulfide nanoparticles. ACS Nano 8, 5670-5681. doi: 10. $1021 / \mathrm{nn} 5002112$

Hanaoka, H., Nagaya, T., Sato, K., Nakamura, Y., Watanabe, R., Harada, T., et al. (2015). Glypican-3 targeted human heavy chain antibody as a drug carrier for hepatocellular carcinoma therapy. Mol. Pharm. 12, 2151-2157. doi: 10.1021/acs. molpharmaceut.5b00132

Hildebrandt, B., Wust, P., Ahlers, O., Dieing, A., Sreenivasa, G., Kerner, T., et al. (2002). The cellular and molecular basis of hyperthermia. Crit. Rev. Oncol. Hematol. 43, 33-56.

Hodi, F. S., O'Day, S. J., McDermott, D. F., Weber, R. W., Sosman, J. A., Haanen, J. B., et al. (2010). Improved survival with ipilimumab in patients with metastatic melanoma. N. Engl. J. Med. 363, 711-723.

Hollingsworth, R. E., and Jansen, K. (2019). Turning the corner on therapeutic cancer vaccines. NPJ Vaccines 4:7. doi: 10.1038/s41541-019-0103-y
Hou, X., Tao, Y., Pang, Y., Li, X., Jiang, G., and Liu, Y. (2018). Nanoparticle-based photothermal and photodynamic immunotherapy for tumor treatment. Int. J. Cancer 143, 3050-3060. doi: 10.1002/ijc.31717

Jo, S. D., Nam, G.-H., Kwak, G., Yang, Y., and Kwon, I. C. (2017). Harnessing designed nanoparticles: current strategies and future perspectives in cancer immunotherapy. Nano Today 17, 23-37.

Kalos, M., and Carl June, H. (2013). Adoptive T cell transfer for cancer immunotherapy in the era of synthetic biology. Immunity 39, 49-60. doi: 10 . 1016/j.immuni.2013.07.002

Kobayashi, H., and Choyke, P. L. (2019). Near-Infrared Photoimmunotherapy of Cancer. Acc. Chem. Res. 52, 2332-2339. doi: 10.1021/acs.accounts.9b0 0273

Krishnamurthy, A., and Jimeno, A. (2017). Atezolizumab: a novel PD-L1 inhibitor in cancer therapy with a focus in bladder and non-small cell lung cancers. Drugs Today 53, 217-237. doi: 10.1358/dot.2017.53.4.2589163

Kroemer, G., Galluzzi, L., Kepp, O., and Zitvogel, L. (2013). Immunogenic cell death in cancer therapy. Annu. Rev. Immunol. 31, 51-72. doi: 10.1146/annurevimmunol-032712-100008

Li, J., Cui, D., Huang, J., He, S., Yang, Z., Zhang, Y., et al. (2019). Organic semiconducting pro-nanostimulants for near-infrared photoactivatable cancer immunotherapy. Angew. Chem. Int. Ed. 58, 12680-12687. doi: 10.1002/anie. 201906288

Li, Y., Li, X., Doughty, A., West, C., Wang, L., Zhou, F., et al. (2019b). Phototherapy using immunologically modified carbon nanotubes to potentiate checkpoint blockade for metastatic breast cancer. Nanomed. Nanotechnol. Biol. Med. 18, 44-53. doi: 10.1016/j.nano.2019.02.009

Li, Y., Li, X., Zhou, F., Doughty, A., Hoover, A. R., Nordquist, R. E., et al. (2019b). Nanotechnology-based photoimmunological therapies for cancer. Cancer Lett. 442, 429-438. doi: 10.1016/j.canlet.2018.10.044

Liang, R., Liu, L., He, H., Chen, Z., Han, Z., Luo, Z., et al. (2018). Oxygen-boosted immunogenic photodynamic therapy with gold nanocages@manganese dioxide to inhibit tumor growth and metastases. Biomaterials 177, 149-160. doi: 10. 1016/j.biomaterials.2018.05.051

Lu, Q., Qi, S., Li, P., Yang, L., Yang, S., Wang, Y., et al. (2019). Photothermally activatable PDA immune nanomedicine combined with PD-L1 checkpoint blockade for antimetastatic cancer photoimmunotherapy. J. Mater. Chem. B 7, 2499-2511. doi: 10.1039/c9tb00089e

Ma, Y., Zhang, Y., Li, X., Zhao, Y., Li, M., Jiang, W., et al. (2019). Near-infrared II phototherapy induces deep tissue immunogenic cell death and potentiates cancer immunotherapy. ACS Nano 13, 11967-11980. doi: 10.1021/acsnano. $9 \mathrm{~b} 06040$

Mallidi, S., Anbil, S., Bulin, A.-L., Obaid, G., Ichikawa, M., and Hasan, T. (2016). Beyond the barriers of light penetration: strategies, perspectives and possibilities for photodynamic therapy. Theranostics 6, 2458-2487.

Mitsunaga, M., Ogawa, M., Kosaka, N., Rosenblum, L. T., Choyke, P. L., and Kobayashi, H. (2011). Cancer cell-selective in vivo near infrared photoimmunotherapy targeting specific membrane molecules. Nat. Med. 17, 1685-1691. doi: 10.1038/nm.2554

Mougel, A., Terme, M., and Tanchot, C. (2019). Therapeutic cancer vaccine and combinations with antiangiogenic therapies and immune checkpoint blockade. Front. Immunol. 10:467. doi: 10.3389/fimmu.2019.00467

Mroz, P., Hashmi, J. T., Huang, Y.-Y., Lange, N., and Hamblin, M. R. (2011). Stimulation of anti-tumor immunity by photodynamic therapy. Expert Rev. Clin. Immunol. 7, 75-91. doi: 10.1586/eci.10.81

Nagaya, T., Friedman, J., Maruoka, Y., Ogata, F., Okuyama, S., Clavijo, P. E., et al. (2019). Host immunity following near-infrared photoimmunotherapy is enhanced with PD-1 checkpoint blockade to eradicate established antigenic tumors. Cancer Immunol. Res. 7, 401-413. doi: 10.1158/2326-6066.CIR-180546

Nagaya, T., Nakamura, Y., Okuyama, S., Ogata, F., Maruoka, Y., Choyke, P. L., et al. (2017). Near-infrared photoimmunotherapy targeting prostate cancer with prostate-specific membrane antigen (PSMA) antibody. Mol. Cancer Res. 15, 1153-1162. doi: 10.1158/1541-7786.MCR-17-0164

Nagaya, T., Nakamura, Y., Sato, K., Harada, T., Choyke, P. L., and Kobayashi, H. (2016a). Near infrared photoimmunotherapy of B-cell lymphoma. Mol. Oncol. $10,1404-1414$. 
Nagaya, T., Nakamura, Y., Sato, K., Zhang, Y.-F., Ni, M., Choyke, P. L., et al. (2016b). Near infrared photoimmunotherapy with an antimesothelin antibody. Oncotarget 7, 23361-23369. doi: 10.18632/oncotarget. 8025

Nagaya, T., Okuyama, S., Ogata, F., Maruoka, Y., Knapp, D. W., Karagiannis, S. N., et al. (2018). Near infrared photoimmunotherapy targeting bladder cancer with a canine anti-epidermal growth factor receptor (EGFR) antibody. Oncotarget 9, 19026-19038. doi: 10.18632/oncotarget.24876

Nakamura, Y. A., Okuyama, S., Furusawa, A., Nagaya, T., Fujimura, D., Okada, R., et al. (2019). Near-infrared photoimmunotherapy through bone. Cancer Sci. 110, 3689-3694. doi: 10.1111/cas.14203

Nam, J., Son, S., Park, K. S., Zou, W., Shea, L. D., and Moon, J. J. (2019). Cancer nanomedicine for combination cancer immunotherapy. Nat. Rev. Mater. 4, 398-414.

Ng, C. W., Li, J., and Pu, K. (2018). Recent progresses in phototherapy-synergized cancer immunotherapy. Adv. Funct. Mater. 28:1804688.

Ogata, F., Nagaya, T., Nakamura, Y., Sato, K., Okuyama, S., Maruoka, Y., et al. (2017). Near-infrared photoimmunotherapy: a comparison of light dosing schedules. Oncotarget 8, 35069-35075. doi: 10.18632/oncotarget.17047

Ogawa, M., Tomita, Y., Nakamura, Y., Lee, M.-J., Lee, S., Tomita, S., et al. (2017). Immunogenic cancer cell death selectively induced by near infrared photoimmunotherapy initiates host tumor immunity. Oncotarget 8, 1042510436. doi: 10.18632/oncotarget.14425

Panzarini, E., Inguscio, V., and Dini, L. (2013). Immunogenic cell death: can it be exploited in PhotoDynamic Therapy for cancer? Biomed Res. Int. 2013:482160. doi: $10.1155 / 2013 / 482160$

Pardoll, D. M. (2012). The blockade of immune checkpoints in cancer immunotherapy. Nat. Rev. Cancer 12, 252-264. doi: 10.1038/nrc3239

Park, W., Cho, S., Han, J., Shin, H., Na, K., Lee, B., et al. (2018). Advanced smartphotosensitizers for more effective cancer treatment. Biomater. Sci. 6, 79-90. doi: $10.1039 / \mathrm{c} 7 \mathrm{bm} 00872 \mathrm{~d}$

Plosker, G. L. (2011). Sipuleucel-T. Drugs 71, 101-108. doi: 10.2165/11206840000000000-00000

Postow, M. A., Callahan, M. K., and Wolchok, J. D. (2015). Immune checkpoint blockade in cancer therapy. J. Clin. Oncol. 33, 1974-1982.

Qiu, H., Tan, M., Ohulchanskyy, T. Y., Lovell, J. F., and Chen, G. (2018). Recent progress in upconversion photodynamic therapy. Nanomaterials 8:E344.

Rajendrakumar, S. K., Uthaman, S., Cho, C.-S., and Park, I.-K. (2018). Nanoparticle-based phototriggered cancer immunotherapy and its domino effect in the tumor microenvironment. Biomacromolecules 19, 1869-1887. doi: 10.1021/acs.biomac.8b00460

Ris, H.-B., Altermatt, H. J., Nachbur, B., Stewart, J., Wang, Q., Lim, C. K., et al. (1993). Effect of drug-light interval on photodynamic therapy with meta-tetrahydroxyphenylchlorin in malignant mesothelioma. Int. J. Cancer 53, 141-146.

Sahin, U., and Türeci, Ö. (2018). Personalized vaccines for cancer immunotherapy. Science 359, 1355-1360. doi: 10.1126/science.aar7112

Sang, W., Zhang, Z., Dai, Y., and Chen, X. (2019). Recent advances in nanomaterial-based synergistic combination cancer immunotherapy. Chem. Soc. Rev. 48, 3771-3810. doi: 10.1039/c8cs00896e

Sato, K., Ando, K., Okuyama, S., Moriguchi, S., Ogura, T., Totoki, S., et al. (2018) Photoinduced ligand release from a silicon phthalocyanine dye conjugated with monoclonal antibodies: a mechanism of cancer cell cytotoxicity after nearinfrared photoimmunotherapy. ACS Cent. Sci. 4, 1559-1569. doi: 10.1021/ acscentsci.8b00565

Sato, K., Watanabe, R., Hanaoka, H., Harada, T., Nakajima, T., Kim, I., et al. (2014). Photoimmunotherapy: comparative effectiveness of two monoclonal antibodies targeting the epidermal growth factor receptor. Mol. Oncol. 8, 620-632. doi: 10.1016/j.molonc.2014.01.006

Shirasu, N., Shibaguchi, H., Yamada, H., Kuroki, M., and Yasunaga, S. I. (2019). Highly versatile cancer photoimmunotherapy using photosensitizer-conjugated avidin and biotin-conjugated targeting antibodies. Cancer Cell Int. 19:299. doi: 10.1186/s12935-019-1034-4

Smyth, M. J., Cretney, E., Kershaw, M. H., and Hayakawa, Y. (2004). Cytokines in cancer immunity and immunotherapy. Immunol. Rev. 202, 275-293.

Wang, C., Xu, L., Liang, C., Xiang, J., Peng, R., and Liu, Z. (2014). Immunological responses triggered by photothermal therapy with carbon nanotubes in combination with anti-CTLA-4 therapy to inhibit cancer metastasis. Adv. Mater. 26, 8154-8162. doi: 10.1002/adma.201402996

Wang, D., Wang, T., Liu, J., Yu, H., Jiao, S., Feng, B., et al. (2016). Acid-activatable versatile micelleplexes for PD-L1 blockade-enhanced cancer photodynamic immunotherapy. Nano Lett. 16, 5503-5513. doi: 10.1021/acs.nanolett.6b01994

Wang, M., Song, J., Zhou, F., Hoover, A. R., Murray, C., Zhou, B., et al. (2019). NIR-triggered phototherapy and immunotherapy via an antigen-capturing nanoplatform for metastatic cancer treatment. Adv. Sci. 6:1802157. doi: 10 . 1002/advs.201802157

Wang, W., Wang, L., Li, Z., and Xie, Z. (2016). BODIPY-containing nanoscale metal-organic frameworks for photodynamic therapy. Chem. Commun. 52, 5402-5405, doi: 10.1039/c6cc01048b

Wei, W., Jiang, D., Ehlerding, E. B., Barnhart, T. E., Yang, Y., Engle, J. W., et al. (2019). CD146-targeted multimodal image-guided photoimmunotherapy of melanoma. Adv. Sci. 6:1801237. doi: 10.1002/advs.201801237

Weiss, T., Weller, M., and Roth, P. (2016). Immunological effects of chemotherapy and radiotherapy against brain tumors. Expert Rev. Anticancer Ther. 16, $1087-$ 1094. doi: 10.1080/14737140.2016.1229600

Xu, J., Xu, L., Wang, C., Yang, R., Zhuang, Q., Han, X., et al. (2017). Near-infraredtriggered photodynamic therapy with multitasking upconversion nanoparticles in combination with checkpoint blockade for immunotherapy of colorectal cancer. ACS Nano 11, 4463-4474. doi: 10.1021/acsnano.7b00715

Yan, S., Zeng, X., Tang, Y. A., Liu, B.-F., Wang, Y., and Liu, X. (2019). Activating antitumor immunity and antimetastatic effect through polydopamineencapsulated core-shell upconversion nanoparticles. Adv. Mater. 31:1905825.

Yin, X., Mead, B. E., Safaee, H., Langer, R., Karp, J. M., and Levy, O. (2016). Engineering stem cell organoids. Cell Stem Cell 18, 25-38. doi: 10.1016/j.stem. 2015.12.005

Zheng, T., Wang, W., Wu, F., Zhang, M., Shen, J., and Sun, Y. (2019) Zwitterionic polymer-gated $\mathrm{Au} @ \mathrm{TiO}_{2}$ core-shell nanoparticles for imagingguided combined cancer therapy. Theranostics 9, 5035-5048. doi: 10.7150/thno. 35418

Zhou, F., Yang, J., Zhang, Y., Liu, M., Lang, M. L., Li, M., et al. (2018). Local phototherapy synergizes with immunoadjuvant for treatment of pancreatic cancer through induced immunogenic tumor vaccine. Clin. Cancer Res. 24, 5335-5346. doi: 10.1158/1078-0432.CCR-18-1126

Conflict of Interest: The authors declare that the research was conducted in the absence of any commercial or financial relationships that could be construed as a potential conflict of interest.

Copyright (C) $2020 \mathrm{Xu}, \mathrm{Lu}$ and Lee. This is an open-access article distributed under the terms of the Creative Commons Attribution License (CC BY). The use, distribution or reproduction in other forums is permitted, provided the original author $(s)$ and the copyright owner(s) are credited and that the original publication in this journal is cited, in accordance with accepted academic practice. No use, distribution or reproduction is permitted which does not comply with these terms. 